Article

\title{
Prediction Model for Mechanical Properties of Lightweight Aggregate Concrete Using Artificial Neural Network
}

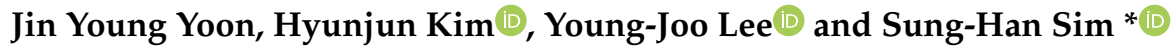 \\ School of Urban and Environmental Engineering, Ulsan National Institute of Science and Technology, \\ Ulsan 44919, Korea \\ * Correspondence: ssim@unist.ac.kr
}

Received: 16 July 2019; Accepted: 19 August 2019; Published: 22 August 2019

\begin{abstract}
The mechanical properties of lightweight aggregate concrete (LWAC) depend on the mixing ratio of its binders, normal weight aggregate (NWA), and lightweight aggregate (LWA). To characterize the relation between various concrete components and the mechanical characteristics of LWAC, extensive studies have been conducted, proposing empirical equations using regression models based on their experimental results. However, these results obtained from laboratory experiments do not provide consistent prediction accuracy due to the complicated relation between materials and mix proportions, and a general prediction model is needed, considering several mix proportions and concrete constituents. This study adopts the artificial neural network (ANN) for modeling the complex and nonlinear relation between constituents and the resulting compressive strength and elastic modulus of LWAC. To construct a database for the ANN model, a vast amount of detailed and extensive data was collected from the literature including various mix proportions, material properties, and mechanical characteristics of concrete. The optimal ANN architecture is determined to enhance prediction accuracy in terms of the numbers of hidden layers and neurons. Using this database and the optimal ANN model, the performance of the ANN-based prediction model is evaluated in terms of the compressive strength and elastic modulus of LWAC. Furthermore, these prediction accuracies are compared to the results of previous ANN-based analyses, as well as those obtained from the commonly used linear and nonlinear regression models.
\end{abstract}

Keywords: artificial neural network; compressive strength; elastic modulus; lightweight aggregate concrete; prediction model

\section{Introduction}

Lightweight aggregate concrete (LWAC) represents a type of concrete which has a low unit weight compared to that of normal weight aggregate concrete (NWAC). Because of the low mass density, LWAC has the advantages associated with reduced self-weight of structures and has been applied in long-span bridges and high-rise buildings [1]. Furthermore, structural LWAC, with a strength that is similar to NWAC, enables the reduction of construction cost as it requires less reinforcement, smaller supporting deck members, beams, and piers, and less earthquake damage. Another important economic benefit of LWAC is the transportation cost savings achieved by improving the lifting efficiency in the construction field and lowering shipping cost, compared to conventional NWAC products. The unique advantages of LWAC allow a wide variety of real world applications that are continuously increasing [2].

LWAC consists of the same concrete components as conventional NWAC with a partial or complete replacement of normal weight aggregate (NWA) with lightweight aggregate (LWA). Commercially 
available artificial LWAs are generally produced by sintering pyroplastic materials such as slate, shale, clay, and by-products of coal combustion materials at $1200-1300{ }^{\circ} \mathrm{C}$ [3]. These LWAs have an inherently great porosity, resulting in low density, low strength, and deformable particles [4,5]. Following ASTM C 330 standard tests [6], these LWAs conform to the specifications of a particle density not exceeding $2000 \mathrm{~kg} / \mathrm{m}^{3}$, or a dry loose bulk density less than $1120 \mathrm{~kg} / \mathrm{m}^{3}, 880 \mathrm{~kg} / \mathrm{m}^{3}$, and $1040 \mathrm{~kg} / \mathrm{m}^{3}$ for fine, coarse, and combined LWA, respectively. LWAC incorporating these LWAs generally has a density lower than $1920 \mathrm{~kg} / \mathrm{m}^{3}$ [7]. A lower density of LWAC can be achieved by using a larger amount of porous LWA, resulting in poor mechanical performance. Because the failure of LWAC is influenced by the friable and deformable LWAs, most LWAC has a lower compressive strength and elastic modulus than NWAC.

Extensive efforts have been made to characterize the relation between LWAC constituents and the mechanical properties of compressive strength and elastic modulus. A previous study showed that the compressive strength and elastic modulus of LWAC were inversely proportional to the volume fraction of LWA [8]. The compressive strength of LWAC also depends on not only the content of LWAs, but also their type $[9,10]$. Hence, these experimental studies indicated that the properties and amount of LWAs influenced the mechanical behavior of LWAC. Furthermore, the mix proportions of LWAC are also essential parameters influencing the performance of LWAC, such as water-to-cement ratio $(\mathrm{w} / \mathrm{c})$ and mass of aggregate, water, and binders including cement, fly ash, and silica fume [11]. Considering these factors, some guidelines were provided for estimating the mechanical properties of LWAC, which were not consistently attainable due to the complexities associated with LWA properties and mix proportions [7,12]. Therefore, the reliable prediction model for mechanical characteristics of LWAC is required to extend its use in the construction with ensuring its performance.

To consider the highly complicated relationship between concrete constituents and properties of cement-based construction materials, researchers have employed artificial neural networks (ANN). An ANN is a numerical model using highly interconnected processing of simple computing elements, referred to as neurons, imitating the structure and functions of biological neural systems of the human brain [13]. In the field of construction materials, ANN methods were applied for modeling concrete properties, including mechanical characteristics, fluidity, and durability using concrete components-related information as input parameters [14-16]. Ni and Wang [14] reported that the single-layer ANN model showed a good prediction accuracy for estimating the 28-day compressive strength of NWAC. Note that the ANN models of 11-7-1 from Ni and Wang [14] and 7-5-3-2 from Oztas et al. [16] in Table 1 indicate 11 inputs, seven neurons in one hidden layer, and one output and seven inputs, five and three neurons in each hidden layer, and two outputs, respectively. Douma et al. [15] likewise used a single hidden layer ANN model for the prediction of fluidity and mechanical properties of self-compacting concrete, where results were well-matched to the target value. In the case of LWAC, Alshihri et al. [17] and Tavakkol et al. [18] investigated the ANN-based estimation of compressive strength of LWAC fabricated in the laboratory environment. In addition, the ANN model having a single hidden layer structure was used for predicting the Poisson ratio [19] and compressive strength based on measured ultrasonic pulse velocity [20]. These experimental results provided the feasibility of the ANN to model the nonlinear relation between various parameters and concrete properties. However, as prediction modeling for LWAC has not been fully studied, further research is still desired, to evaluate the optimal ANN architecture and consider extensive data about mix proportions, binders, and aggregates.

This study presents an ANN-based prediction model for mechanical characteristics of LWAC, which enable us to produce high-quality LWAC that satisfies the target performance. First, detailed and extensive data on the mix proportions and the mechanical behavior of LWAC are collected from the literature. The vast amount of data allows to enhance the reliability and accuracy of the prediction model. Input parameters for the ANN model are selected for better modeling of the LWAC, including water-to-binder ratio, amount of binders, density of concrete, and volume fraction of aggregates. Subsequently, the appropriate number of hidden layers and neurons are determined for developing the optimal ANN architectures to obtain high prediction accuracy. Finally, the performance of the 
ANN-based prediction model is evaluated and compared to the results obtained from the commonly used statistical models.

\section{Research Background}

\subsection{Artificial Neural Network}

An ANN is a network based on a collection of connected neurons used to model the complex relationship between inputs and outputs. As shown in Figure 1, the basic structure of an ANN consists of three types of layers: Input, hidden, and output layers. Depending on the number of hidden layers, ANN is classified into single- or multi-layer perceptron, which has multi-connected neurons. When neurons in the input layer receive an input, the weighted sums of the inputs are transferred to interconnected neurons in the next layer and evaluated using activation functions [13]. The weight and bias values can be determined as the solutions of the optimization problem to minimize the prediction error using the back-propagation algorithm [15].

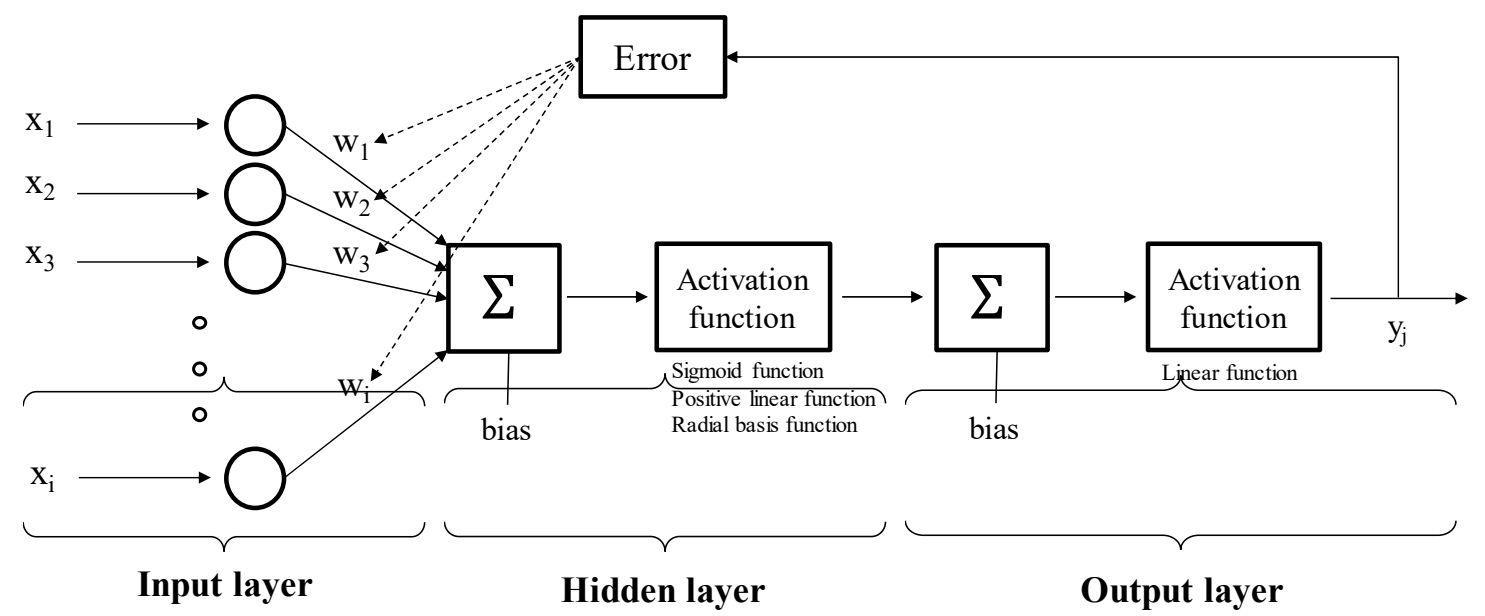

Figure 1. Schematic diagram for artificial neural network [21].

To optimize the weight and bias, the back-propagation learning is repeated from the output layer back to the input layer in each running step, until there is no further decrease in the mean square error (MSE) of the prediction. After the training is completed with updated weight and bias, new inputs from the test dataset are used in the network to produce the corresponding outputs. The prediction accuracy can be evaluated by the mean absolute percentage error $(M A E)$ and correlation coefficient $(R)$. $M S E, M A E$, and $R$ are defined as:

$$
\begin{gathered}
M S E=\frac{1}{N} \sum\left(y_{i}-y_{d i}\right)^{2} \\
M A E=\frac{1}{N} \sum \frac{\left|y_{i}-y_{d i}\right|}{\left|y_{i}\right|} \\
R=\frac{\sum\left(y_{i}-\bar{y}_{i}\right)\left(y_{d i}-\bar{y}_{d i}\right)}{\sqrt{\sum\left(y_{i}-\bar{y}_{i}\right)^{2} \sum\left(y_{d i}-\bar{y}_{d i}\right)^{2}}}
\end{gathered}
$$

where $N$ is the number of training data, $y_{i}$ is the target value, $y_{d i}$ is the predicted result, $y_{i}$ is the mean prediction value, and $y_{d i}$ is the mean target value. The correlation coefficient is introduced to evaluate the linear dependence between the predicted and target values. Its value ranges from -1 to 1 , where 1 indicates the perfect positive correlation and 0 means no linear relation among variables. 


\subsection{ANN-Based Prediction of Concrete Properties}

Previous ANN-based prediction models demonstrated the feasibility for predicting physical and mechanical properties of concrete, as provided in Table 1. The most conventionally used ANN-based prediction mainly focused on the characterization of properties of NWAC, such as the compressive strength, elastic modulus, drying shrinkage, and fluidity [14,22-25]. As these ANN models exhibited acceptable prediction accuracy, their applications were extended to high strength concrete, self-consolidating concrete, recycled aggregate concrete, and LWAC. However, further research on these types of concrete is still needed to enhance the reliability and the prediction accuracy of ANN-based analysis considering various mix proportions and concrete materials. Furthermore, determining optimal numbers of hidden layers and neurons for the ANN model is necessary to model a complex relationship between the inputs and targets. Considering these aspects, this study mainly focuses on the prediction of mechanical properties of LWAC using the ANN model.

Table 1. Previous studies using artificial neural network (ANN) analysis for predicting mechanical behavior of cement-based material.

\begin{tabular}{ccc}
\hline Literature & Target & $\begin{array}{c}\text { ANN Architecture } \\
\text { (Number of Neurons in } \\
\text { Input-Hidden-Output Layers) }\end{array}$ \\
\hline Ni and Wang (2000) [14] & Compressive strength (65 data) & $11-7-1$ \\
\hline Oztas et al. (2006) [16] & $\begin{array}{c}\text { Compressive strength and fluidity } \\
\text { (187 data) }\end{array}$ & $7-5-3-2$ \\
\hline Demir (2008) [22] & Elastic modulus (159 data) & $1-3-1,1-5-1,1-3-3-1$ \\
\hline Alshihri et al. (2009) [17] & Compressive strength (108 data) & $8-14-4,8-14-6-4$ \\
\hline Atici (2011) [23] & Compressive strength (27 data) & $3-5-1,4-6-1,4-6-1$ \\
\hline Bal and Buyle-Bodin (2013) [24] & Drying shrinkage (176 data) & $3-5-1,5-6-1,2-4-1$ \\
\hline Khademi et al. (2016) [26] & Compressive strength (257 data) & $11-8-4-1,11-8-6-1$ \\
\hline Douma et al. (2017) [15] & Fluidity (114 data) & $14-29-1$ \\
\hline Hossain et al. (2018) [25] & Compressive and tensile strength \\
(180 data) & $6-17-1$ \\
\hline
\end{tabular}

In the application of the ANN model, several issues have been identified with regard to the database, input variables, and ANN architecture. First, many studies used the data obtained in the laboratory environment, resulting in an acceptable prediction error $[14,17,18]$. However, the applications of these ANN models are limited to the concrete using specific types of materials. To make a more general ANN-based prediction model, this study collects various data of LWAC mixtures with different mix proportions and concrete materials provided in Section 3. The selection of appropriate input parameters is another important factor to consider for obtaining high prediction accuracy. Considering the input variables used in previous studies and the unique material properties of LWAC, the inputs are determined as shown in Section 4.1. Lastly, the investigation for designing optimal ANN architecture for predicting mechanical properties of LWAC is necessary in terms of the numbers of hidden layers and neurons. Previous studies, listed in Table 1, used various ANN models with one- and two-hidden layers with 3-29 hidden neurons. As an example, 11-7-1 in Ni and Wang [14] depicts 11 inputs, seven neurons in one hidden layer, and one output ANN architecture. Because these experimental studies attained a good prediction accuracy, this study conducts the ANN analysis using the ANN model with the range of these hidden layers and neurons, as provided in Section 4.2. Finally, vast data, suitable input variables, and optimal ANN architecture are used for the ANN-based prediction model for LWAC. 


\section{Establishment of A Database}

Accurate and reliable prediction using the ANN model generally depends on the amount and quality of available data. This study conducted a literature review to collect extensive and detailed information on mix proportions, physical properties of composites, and mechanical characteristics of concrete. A total of 149 concrete mixtures (20 NWAC and 129 LWAC) produced with various mix proportion and aggregates were prepared for ANN-based compressive strength analysis $[2,4,8,10,27-37]$. For the prediction of the static elastic modulus, data from 133 concrete mixtures (20 NWAC and 113 LWAC) were collected $[2,4,8,10,27,28,32-37]$. The obtained data are summarized in Table 2 listing concrete density $\left(\mathrm{kg} / \mathrm{m}^{3}\right)$, water-to-binder ratio $(\mathrm{w} / \mathrm{b})$, content of water $\left(\mathrm{kg} / \mathrm{m}^{3}\right)$, cement $\left(\mathrm{kg} / \mathrm{m}^{3}\right)$, fly ash $\left(\mathrm{kg} / \mathrm{m}^{3}\right)$, silica fume $\left(\mathrm{kg} / \mathrm{m}^{3}\right)$, coarse NWA $\left(\mathrm{CNWA}, \mathrm{kg} / \mathrm{m}^{3}\right)$, fine NWA (FNWA, $\mathrm{kg} / \mathrm{m}^{3}$ ), coarse LWA $\left(C L W A, \mathrm{~kg} / \mathrm{m}^{3}\right.$ ), fine LWA (FLWA, $\mathrm{kg} / \mathrm{m}^{3}$ ), volume fraction of aggregate, and the specific gravity of used materials. Detailed information on concrete mixtures is provided in the Appendix A. Note that NWAC is included in the database as control concrete samples without CLWA and FLWA. Compared to the mix proportion of LWAC, the selected data of NWAC have a similar w/b ratio, cement, fly ash, and silica fume content. The variables of mix proportion and volume fraction provided in Table 2 are generally considered as factors influencing the mechanical behavior of concrete [17].

Table 2. Database for ANN analysis.

\begin{tabular}{|c|c|c|c|}
\hline \multicolumn{2}{|c|}{ Mix Proportion and Material Properties } & LWAC & NWAC \\
\hline \multicolumn{2}{|c|}{ Concrete density } & $1170-2280 \mathrm{~kg} / \mathrm{m}^{3}$ & $2030-2430 \mathrm{~kg} / \mathrm{m}^{3}$ \\
\hline \multicolumn{2}{|c|}{$\mathrm{w} / \mathrm{b}$} & $0.23-0.55$ & $0.25-0.45$ \\
\hline \multirow{8}{*}{ Mass } & Water & $150-263 \mathrm{~kg} / \mathrm{m}^{3}$ & $158-207 \mathrm{~kg} / \mathrm{m}^{3}$ \\
\hline & Cement & $300-710 \mathrm{~kg} / \mathrm{m}^{3}$ & $300-640 \mathrm{~kg} / \mathrm{m}^{3}$ \\
\hline & Fly ash & $0-300 \mathrm{~kg} / \mathrm{m}^{3}$ & $0-300 \mathrm{~kg} / \mathrm{m}^{3}$ \\
\hline & Silica fume & $0-71 \mathrm{~kg} / \mathrm{m}^{3}$ & $0-96 \mathrm{~kg} / \mathrm{m}^{3}$ \\
\hline & CNWA & $0-810 \mathrm{~kg} / \mathrm{m}^{3}$ & $810-1105 \mathrm{~kg} / \mathrm{m}^{3}$ \\
\hline & FNWA & $0-1096 \mathrm{~kg} / \mathrm{m}^{3}$ & $288-861 \mathrm{~kg} / \mathrm{m}^{3}$ \\
\hline & CLWA & $0-898 \mathrm{~kg} / \mathrm{m}^{3}$ & 0 \\
\hline & FLWA & $0-631 \mathrm{~kg} / \mathrm{m}^{3}$ & 0 \\
\hline \multirow{4}{*}{ Volume fraction } & CNWA & $0-0.31$ & $0.30-0.45$ \\
\hline & FNWA & $0-0.42$ & $0.12-0.34$ \\
\hline & CLWA & $0-0.52$ & 0 \\
\hline & FLWA & $0-0.39$ & 0 \\
\hline \multirow{7}{*}{ Specific gravity } & Cement & \multicolumn{2}{|c|}{$3100-3160 \mathrm{~kg} / \mathrm{m}^{3}$} \\
\hline & Fly ash & \multicolumn{2}{|c|}{$2060-2470 \mathrm{~kg} / \mathrm{m}^{3}$} \\
\hline & Silica fume & \multicolumn{2}{|c|}{$2000-2280 \mathrm{~kg} / \mathrm{m}^{3}$} \\
\hline & CNWA & \multicolumn{2}{|c|}{$2460-2740 \mathrm{~kg} / \mathrm{m}^{3}$} \\
\hline & FNWA & \multicolumn{2}{|c|}{$2460-2700 \mathrm{~kg} / \mathrm{m}^{3}$} \\
\hline & CLWA & \multicolumn{2}{|c|}{$600-2070 \mathrm{~kg} / \mathrm{m}^{3}$} \\
\hline & FLWA & \multicolumn{2}{|c|}{$1340-1790 \mathrm{~kg} / \mathrm{m}^{3}$} \\
\hline
\end{tabular}

Because several studies used different sizes of specimens for measuring the compressive strength and elastic modulus, the size effect needs to be considered to assure data consistency. The size effect generally presents a reduction of compressive strength and the elastic modulus of concrete with an increasing the height-to-width ratio caused by failure of the heterogeneous concrete composite [38]. Therefore, the correction factors are used to convert the data of compressive strength and elastic modulus to equivalent values for the widely used $100 \mathrm{~mm}$ by $200 \mathrm{~mm}$ cylindrical specimen, referring to the empirical equations from previous studies [38-41]. Here, the correction factors for 28-day compressive strength are 1.051 for $f_{c, \varnothing 100 \times 200} / f_{c, 150 \times 150 \times 150}, 0.874$ for $f_{c, \varnothing 100 \times 200} / f_{c, 100 \times 100 \times 100}$, and 1.230 for $f_{c, \varnothing 100 \times 200} / f_{c, \varnothing 150 \times 300}$ obtained from $\mathrm{w} / \mathrm{c}=0.49$ high performance lightweight foamed concrete [42]. The correction equation for the static elastic modulus is $E_{c, \varnothing 100 \times 200}=\left(E_{c, \varnothing 150 \times 300}-1.9\right) / 0.9$ obtained 
from normal strength NWAC [41]. Because the investigations of size and shape effect for LWAC were rare, the empirical equations from foamed concrete and normal strength NWAC are used considering the similar failure mechanism induced by the concrete heterogeneity and internal defects of voids. Using these correction factors for the compressive strength and elastic modulus, the database used for the ANN model is updated.

\section{Prediction Model for Compressive Strength and Elastic Modulus Using ANN}

Because the ANN model has been used for modeling highly nonlinear and complex interactions between input and output variables, the selection of appropriate input parameters and the ANN architecture is critical for reliable and accurate prediction. This section mainly illustrates the selection of input factors and the determination of the optimal ANN architecture for the prediction of mechanical characteristics of LWAC.

\subsection{Input Parameters}

The selection of appropriate input variables is an important task for enhancing the prediction accuracy of the ANN model, considering the relation between input and target values. Because the strong correlation between mechanical properties of concrete and the amount of constituent materials is generally known, these parameters were adopted as the input for predicting compressive strength and the elastic modulus using ANN models, as summarized in Table $3[15-17,26]$. Commonly used inputs are $\mathrm{w} / \mathrm{b}$ ratio and mass of water, binders, aggregates, and chemical admixture, which are likewise adopted in this study. However, other parameters such as the sand-to-aggregate ratio, aggregate-to-binder ratio, replacement ratio of binders and aggregates, grade of cement, maximum size of aggregates, and the fine modulus of sand are not included despite their possible relation with mechanical properties, because of the difficulties in data collection, as in [14,43]. Even though previous studies listed in Table 3 provide useful information about the selection of appropriate inputs, NWAC was of primary interest in the prediction. Therefore, additional variables tailored to LWAC are needed to improve the prediction performance.

Table 3. Input variables for the ANN model.

\begin{tabular}{cc}
\hline & $\begin{array}{c}\text { Input Variables } \\
\text { Oztas et al. [16] }\end{array}$ \\
$\begin{array}{c}\text { w/b ratio, sand-to-aggregate ratio, replacement ratio } \\
\text { of fly ash and silica fume, mass of water, } \\
\text { chemical admixture }\end{array}$ \\
\hline Alshihri et al. [17] & $\begin{array}{c}\text { w/c ratio, curing period, mass of FNWA, CLWA, } \\
\text { FLWA, silica fume, chemical admixture }\end{array}$ \\
\hline Khademi et al. [26] & $\begin{array}{c}\text { w/c ratio, aggregate-to-cement ratio, replacement } \\
\text { ratio of recycled aggregate, water-to-total materials } \\
\text { ratio, mass of water, cement, CNWA, FNWA, recycled } \\
\text { aggregate, chemical admixture }\end{array}$ \\
\hline Douma et al. [15] & $\begin{array}{c}\text { w/b ratio, replacement ratio of fly ash, content of } \\
\text { binders, CNWA, FNWA, chemical admixture }\end{array}$ \\
\hline ANN model & $\begin{array}{c}\text { w/b ratio, concrete density, mass of water, cement, fly } \\
\text { ash, silica fume, volume fraction of CNWA, FNWA, } \\
\text { CLWA, FLWA }\end{array}$ \\
\hline
\end{tabular}

Accordingly, this study adopts the density of LWAC and volume fraction of aggregates as the inputs due to the inverse proportional relation to the mechanical performance of LWAC [44]. Because the linear and nonlinear empirical relation between the density of LWAC and compressive strength or elastic modulus has been reported, the use of this value as an input parameter is expected to enhance the prediction accuracy $[45,46]$. Furthermore, the volume fractions of aggregates are introduced as 
an input parameter regarding the amount of LWA in the mixture, replacing the mass. The volume fraction that reflects the actual volume of added LWA can be viewed as another indicator of how much LWA is contained in the mixture in addition to the mass. Thus, the volume fractions are included as the input variables for NWA for comparison.

In summary, the selected input variables used for the ANN model are w/b ratio, concrete density, mass of water, cement, fly ash, silica fume, and volume fraction of CNWA, FNWA, CLWA, and FLWA as provided in Table 3. In the analysis of compressive strength and elastic modulus, these inputs are adopted for the ANN-based prediction.

\subsection{Determination of the Optimal ANN Architecture}

Determination of the optimal ANN architecture in terms of the number of hidden layers and neurons is the most fundamental part of ANN-based analysis. An excessive number of hidden neurons can cause an over-fit problem due to overestimation in the complex relationship between inputs and targets. An insufficient number of hidden neurons can cause an underfitting problem due to the lack of neurons covering various inputs. Therefore, this study determines the optimal ANN architecture with the minimum MSE value, conducting the tests with consideration to various numbers of hidden layers and neurons. The testing ranges of the numbers of hidden layers and neurons are selected by referring the proposed optimization methodologies and previously applied ANN models. First, many optimized methodologies have been proposed to find appropriate numbers of hidden neurons in the higher-order ANN. Among these methods, three empirical equations are selected to estimate the number of neurons in hidden layers, considering the numbers of inputs and outputs in the ANN models [47-49]. The equations are provided as

$$
\begin{gathered}
N_{h}=\frac{\sqrt{1+8 N_{i}}-1}{2} \\
N_{h}=N_{i}-1 \\
N_{h}=\frac{4 N_{i}^{2}+3}{N_{i}^{2}-8}
\end{gathered}
$$

where $N_{h}$ and $N_{i}$ are the number of hidden neurons and inputs, respectively. Because a total of 10 input parameters are selected in the previous section, the corresponding numbers of calculated hidden neurons are 4, 9, and 4.4 from Equations (4)-(6), respectively. Furthermore, the architectures of previously applied ANN models (see Table 1) are considered to select the appropriate testing ranges. The applied ANN architectures had a higher number of neurons ranging from 3-29 with one or two hidden layers. Thus, to determine the optimal ANN architecture, this study considers the number of neurons from one to 30, which includes the recommended values from Equations (4)-(6) as well as the used ones in Table 1. In the case of hidden layers in the ANN model, previous studies adopted oneor two- hidden layer ANN models, which showed acceptable prediction accuracy. To evaluate the performance of multi-hidden layer ANN models, this study selects a wide range of hidden layers from 1 to 10 .

To determine the optimal ANN architecture with the lowest prediction MSE for testing data, detailed information of the ANN model is provided regarding the backpropagation algorithm, activation function, five-fold cross validation, and used computing resources. This study employs the scaled conjugate gradient backpropagation as a network training scheme that updates weight and bias values according to the scaled conjugate gradient method provided in the MATLAB Deep Learning Toolbox [50]. A nonlinear hyperbolic tangent sigmoid function is employed as an activation function in the hidden layer, and a linear transfer function is used in the output layer. To enhance the reliability of the ANN model, five-fold cross validation is used [51,52]. Once five sets of approximately equal-sized samples are prepared through the random partition process, a subset of each sample is used to fit the ANN model, and the remaining samples evaluate the prediction accuracy of the model. This is 
repeated five times. The network error is the average error obtained from the five-fold cross validation method providing greater confidence in the error evaluation. The evaluation of prediction accuracy is conducted using the following computing resources: Intel(R) Core i5-6600 3.3 GHz (4 CPUs), NVIDIA GeForce GTX 1080, and 8 GB RAM.

In the determination of the optimal ANN architecture, the averaged MSE obtained is used for reliable ANN-based prediction. To show the convergence of averaged MSE values, the relative MSE defined as $(M S E(1)-M S E(i)) / M S E(1)$ is calculated for 50 repetitions, as shown in Figure 2. The results of the relative $M S E$ show a convergence of averaged MSE for multiple repetitions, compared to the result of $M S E(1)$. Due to the high computational cost during the test, the appropriate number of repetitions needs to be selected based on the regression curve from the relative MSE of compressive strength and elastic modulus, marked as "Comp" and "Els" in Figure 2, respectively. The regression curve is $-0.148 x^{-3.812}+0.148$ for compressive strength and $-0.176 x^{-3.391}+0.176$ for the elastic modulus. When the slope of $10^{-4}$ is selected as a threshold of convergence, the minimum numbers of the required repetitions are 7 and 8 for the compressive strength and elastic modulus, respectively, which yield the corresponding MSE values.

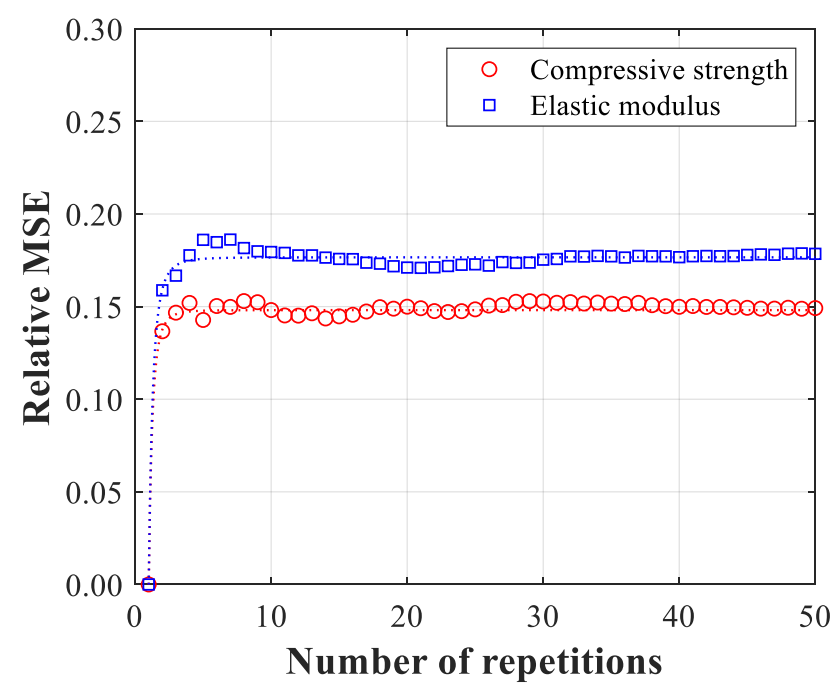

Figure 2. Relative MSE for compressive strength and elastic modulus.

In the prediction of the compressive strength and elastic modulus, the optimal ANN architecture is determined considering MSE values for training and testing and computation time. The MSE results for both training and testing are provided in Figure 3 obtained by the ANN models with the 1-30 neurons and 1-10 hidden layers. As expected, the prediction results for both the compressive strength and elastic modulus show much lower MSE values in training than in testing. When the optimal architecture of the ANN model is determined at the minimum test MSE, as provided in Table 4, two hidden layers with 14 neurons in each hidden layer for compressive strength analysis show the best performance with the training and a test MSE of 48.7 and 98.2, respectively. For the elastic modulus analysis, the minimum training and test MSE values are 7.8 and 16.9 , respectively, corresponding to four hidden layers and 23 neurons. The training times depicted in Figure 3e,f show that a greater number of hidden layers for given number of neurons increases the computational cost significantly due to more numerical calculation. An overfitting problem at small numbers of hidden neurons and many hidden layers is related to the vanishing gradient problem due to slower optimization in earlier layers than in later layers [53]. 


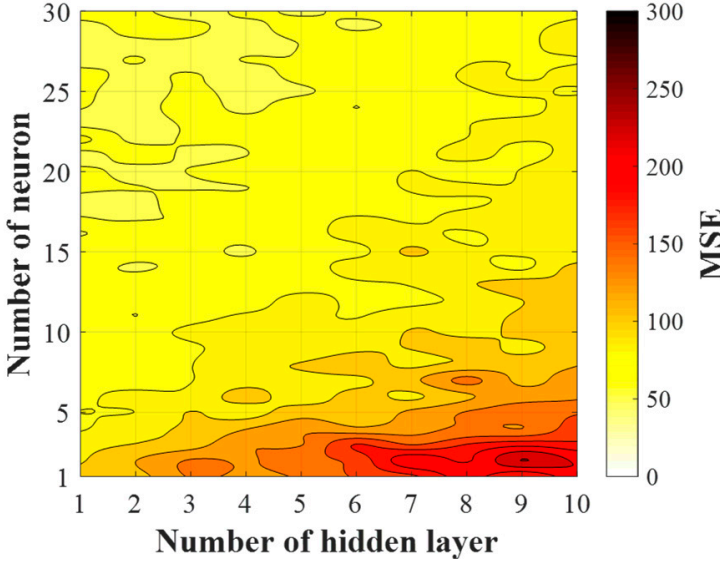

(a)

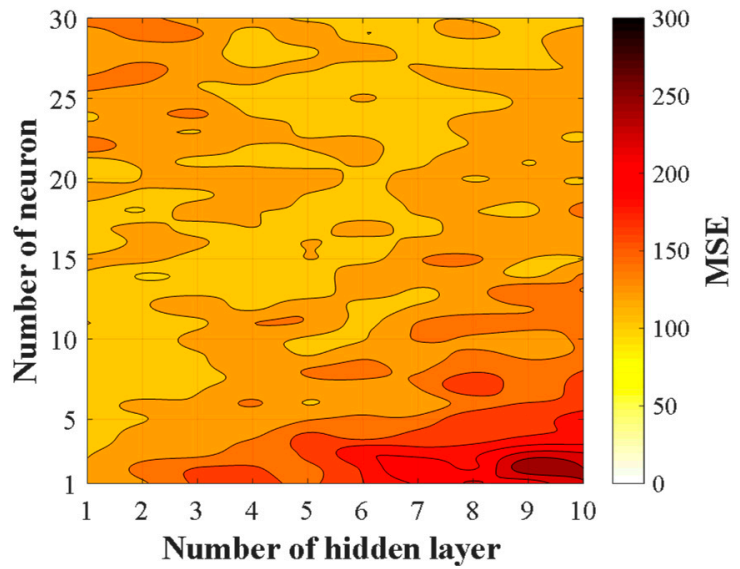

(c)

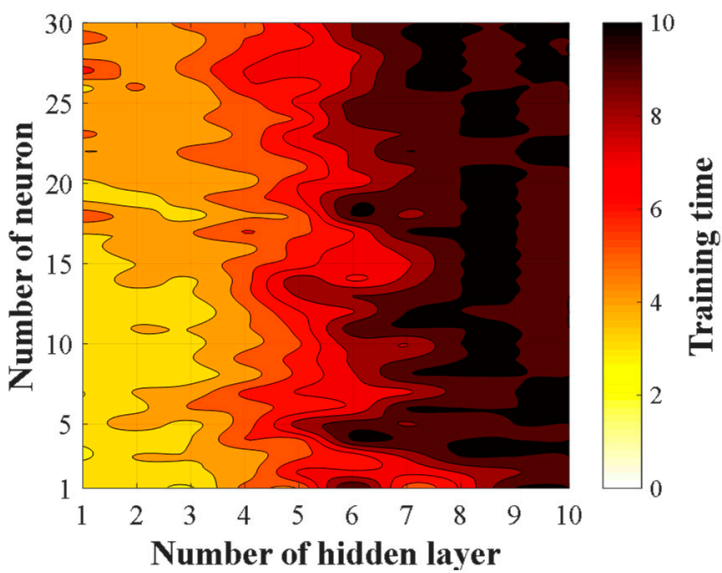

(e)

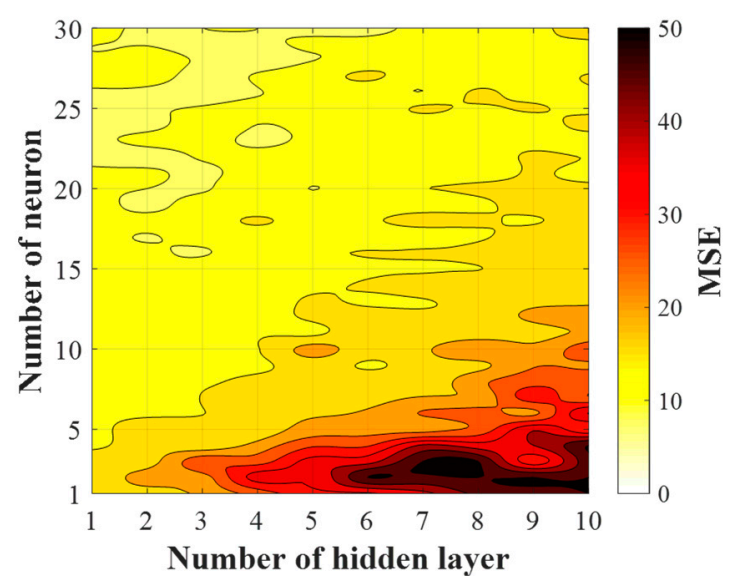

(b)

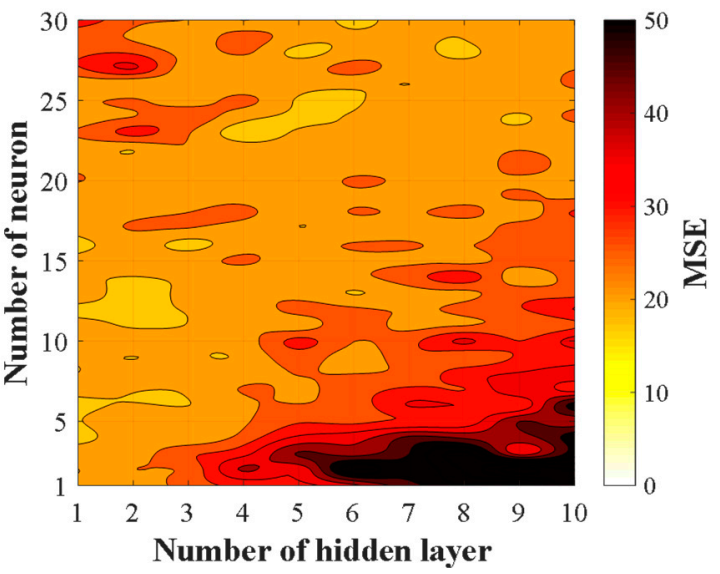

(d)

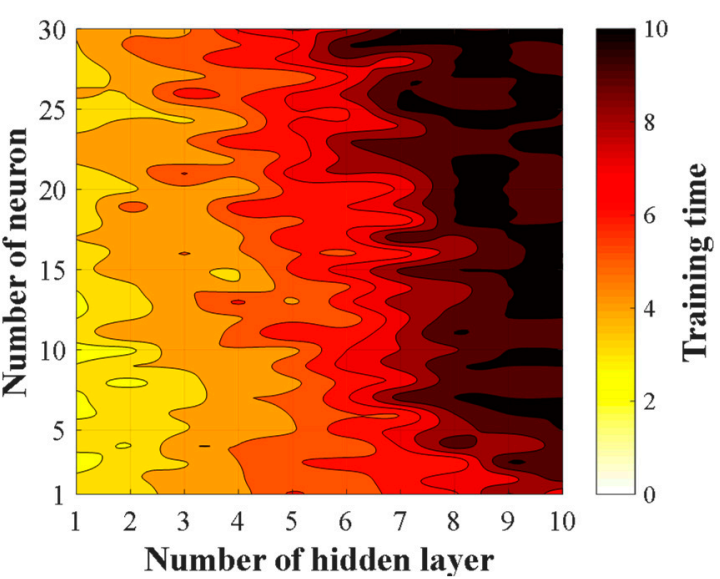

(f)

Figure 3. ANN performance evaluation: (a) training, (c) test, and (e) training time for compressive strength and (b) training, (d) test, and (f) training time for elastic modulus analyses.

Table 4. Optimal architecture and prediction accuracy of the ANN model.

\begin{tabular}{ccc}
\hline ANN Model & $\begin{array}{c}\text { Prediction for } \\
\text { Compressive Strength }\end{array}$ & $\begin{array}{c}\text { Prediction for } \\
\text { Elastic Modulus }\end{array}$ \\
\hline Number of layers & 2 & 4 \\
Number of neurons & 14 & 23 \\
Training $M S E$ & 48.7 & 7.8 \\
Test $M S E$ & 98.2 & 16.9 \\
\hline
\end{tabular}




\section{Evaluation of Prediction Accuracy}

Using the input variables and optimal ANN architecture determined in the previous section, the performance of the ANN-based prediction model is evaluated with respect to the compressive strength and elastic modulus of LWAC. Furthermore, the prediction results are compared to those obtained from the linear and nonlinear regression models using the same input data.

\subsection{Prediction Results Using the ANN Model}

Prediction accuracies for compressive strength and elastic modulus of LWAC are evaluated using the selected inputs and ANN architectures with respect to the square error, $M A E$, and correlation coefficient. Figure 4 shows the ANN-based prediction results with the square errors of each input data, when the ANN models have two hidden layers and 14 neurons, and four layers and 23 neurons for estimation of the compressive strength and elastic modulus, respectively. For the compressive strength analysis, the square error ranges from $1.3 \times 10^{-3}$ to $6.2 \times 10^{2}$ and from $3.6 \times 10^{-2}$ to $2.9 \times 10^{2}$ for training and testing, respectively. $M A E$ values are $9.6 \%$ and $14.5 \%$ for training and testing, respectively. Furthermore, $87 \%$ of the testing data has $M A E$ values of less than $30 \%$, while the correlation coefficient of the predicted and reference data is 0.930 . Prediction results for the elastic modulus show better accuracy. The square error ranges from $1.5 \times 10^{-4}$ to $8.5 \times 10$ for training and from $6.5 \times 10^{-5}$ to $4.4 \times 10$ for testing. MAE values are $6.9 \%$ and $8.5 \%$ for training and testing, respectively, which depicts results that are much lower than those for the compressive strength. In addition, the square error of the individual testing data does not exceed a $M A E$ of $30 \%$, resulting in a high correlation coefficient of 0.977 . Note that the large variations of square error for compressive strength are derived from its raw data of compressive strength having larger variation than that of the elastic modulus. These prediction errors obtained from the ANN models are summarized in Table 5. Compared to the prediction accuracy of the ANN model for NWAC, less than $12.4 \%$ of $M A E$, reported by previous studies listed in Table 1, the present ANN-based model for LWAC exhibits acceptable performance for predicting the compressive strength and elastic modulus.
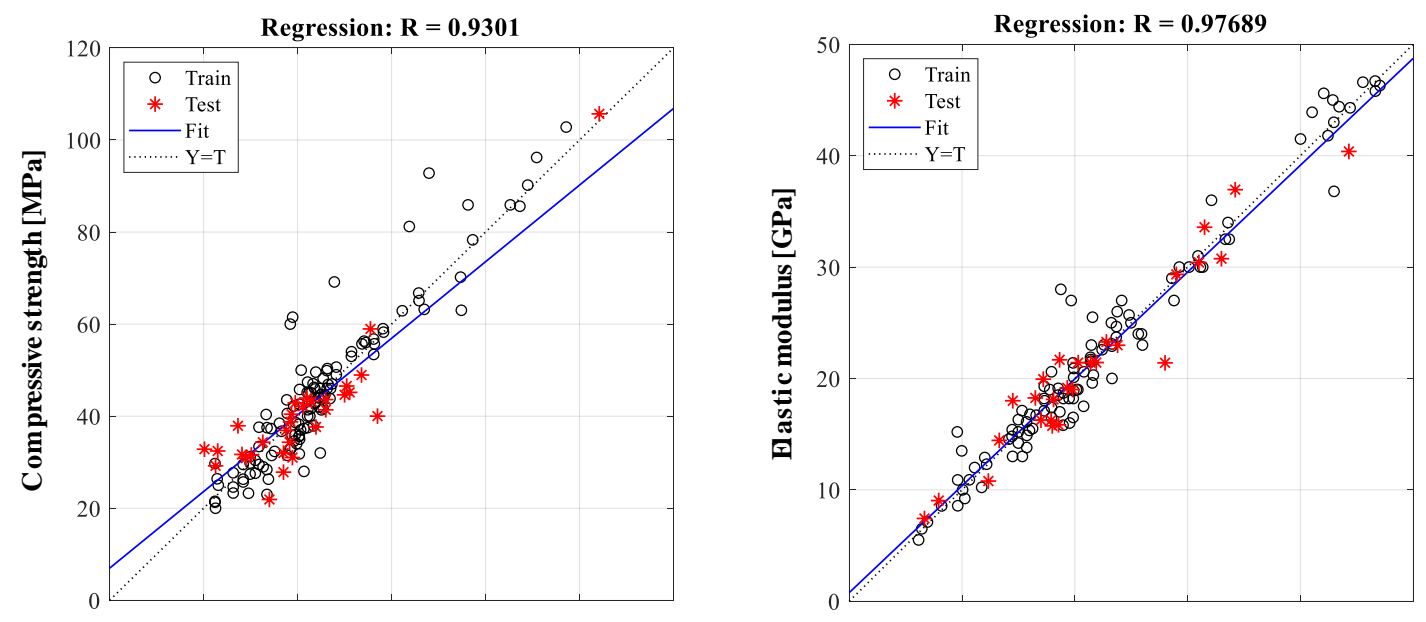

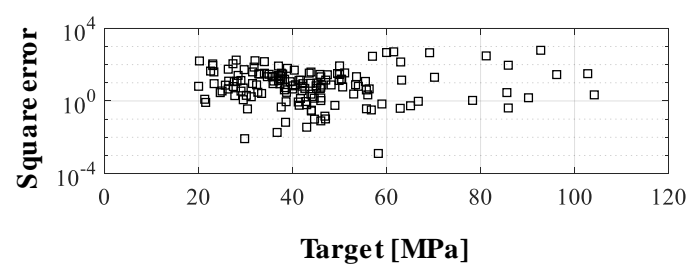

(a)

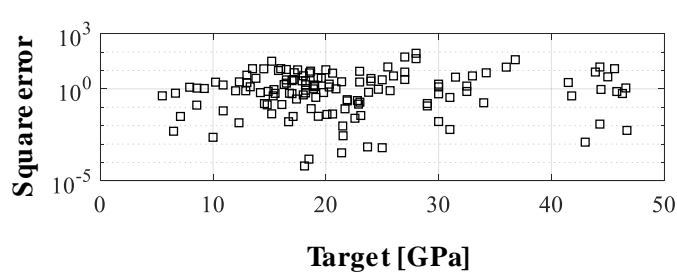

(b)

Figure 4. Prediction results from ANN model: (a) compressive strength and (b) elastic modulus. 
Table 5. Prediction accuracy of ANN-based models.

\begin{tabular}{ccccc}
\hline \multirow{2}{*}{$\begin{array}{c}\text { Error } \\
\text { Configuration }\end{array}$} & \multicolumn{2}{c}{ Compressive Strength } & \multicolumn{2}{c}{ Elastic Modulus } \\
\cline { 2 - 5 } & Training & Test & Training & Test \\
\hline Square error & $1.3 \times 10^{-3}-6.2 \times 10^{2}$ & $3.6 \times 10^{-2}-2.9 \times 10^{2}$ & $1.5 \times 10^{-4}-8.5 \times 10$ & $6.5 \times 10^{-5}-4.4 \times 10$ \\
\hline$M A E$ & $9.6 \%$ & $14.5 \%$ & $6.9 \%$ & $8.5 \%$ \\
\hline $\begin{array}{c}\text { Correlation } \\
\text { coefficient }\end{array}$ & 0.930 & & 0.977 \\
\hline
\end{tabular}

\subsection{Comparative Analysis}

In Section 5.1, the prediction performance of the ANN model is validated, and the results are compared to those obtained from the commonly used regression algorithms: The statistical models of linear and nonlinear regression. These regression models have typically been used for modeling the relationship between constituents and concrete properties $[18,45,46]$. Thus, this study adopts the linear and nonlinear (i.e., second-order polynomial) regression models for the evaluation of prediction performance. Furthermore, their prediction accuracies are compared to those obtained from the ANN models using scale-independent $M A E$.

In the linear regression model, multiple linear regression (MLR) is employed to identify the relationship between two or more independent variables and the dependent variable. The equation for the generally used MLR model is provided as

$$
y=\alpha_{0}+\alpha_{1} x_{1}+\alpha_{2} x_{2}+\cdots+\alpha_{i} x_{i}
$$

where $y$ depicts the properties of LWAC being predicted, $x_{i}$ depicts the independent variables, $\alpha_{0}$ is the $y$-intercept, and $\alpha_{i}$ is the regression coefficient. Using the same input variables and data randomly divided into an 8:2 ratio for training and testing likewise the ANN model, the coefficients are optimized with respect to minimizing the summed square error between predicted and target values. The residuals from MLR model are equally distributed and homoscedastic. Due to the variance of network errors at every analysis, MLR-based predictions are repeated 10 times. The linear regression model with the minimum $M A E$ value for test is provided, as shown in Figure 5. The prediction-accuracy indicators for the compressive strength are $87.3,16.4 \%$, and 0.841 for the MSE, MAE, and correlation coefficient, respectively. For the elastic modulus, Figure $5 \mathrm{~b}$ shows the MLR-based prediction as $12.9,14.4 \%$, and 0.921 for the MSE, MAE, and correlation coefficient, respectively. The relatively high prediction errors from MLR-based analysis could be related to the assumption that the relationship between the mixture components and concrete properties is linear.

Considering the complex and nonlinear relationships between the constituents and concrete properties, the nonlinear models employing higher-order polynomials help improve the prediction results. In this study, the multiple nonlinear regression (MNLR) model contains constant, linear, and quadratic terms as follows:

$$
y=\alpha_{0}+\alpha_{1} x_{1}+\alpha_{2} x_{2} \cdots+\alpha_{i} x_{i}+\beta_{1} x_{1}^{2}+\beta_{2} x_{2}^{2}+\cdots+\beta_{i} x_{i}^{2}
$$

where $\beta_{i}$ is the coefficient for $x_{i}^{2}$. The coefficients of the nonlinear regression model are likewise determined by minimizing the square error between estimated and target values. The same database used in the ANN model is applied for MNLR-based analysis, with an 8:2 ratio for training to testing data quantities. The residuals from MNLR model are also equally distributed and homoscedastic likewise MLR model. The training data optimize the coefficients of the MNLR model, and the prediction performance of this model is evaluated. The prediction results with the minimum prediction error are selected on the basis of the 10 times repetitions, as shown in Figure 6. For the compressive strength prediction, the prediction results are $64.2,15.0 \%$, and 0.880 for the MSE, MAE, and correlation 
coefficient, respectively. Figure $6 \mathrm{~b}$ shows the results of the elastic modulus with values of $17.6,13.4 \%$, and 0.944 for the MSE, MAE, and correlation coefficient. As expected, the quadratic polynomial-based MNLR model demonstrates a better prediction accuracy than the result obtained from the MLR model. Despite the improvement of prediction accuracy using the MNLR model, the ANN-based model shows a better performance.
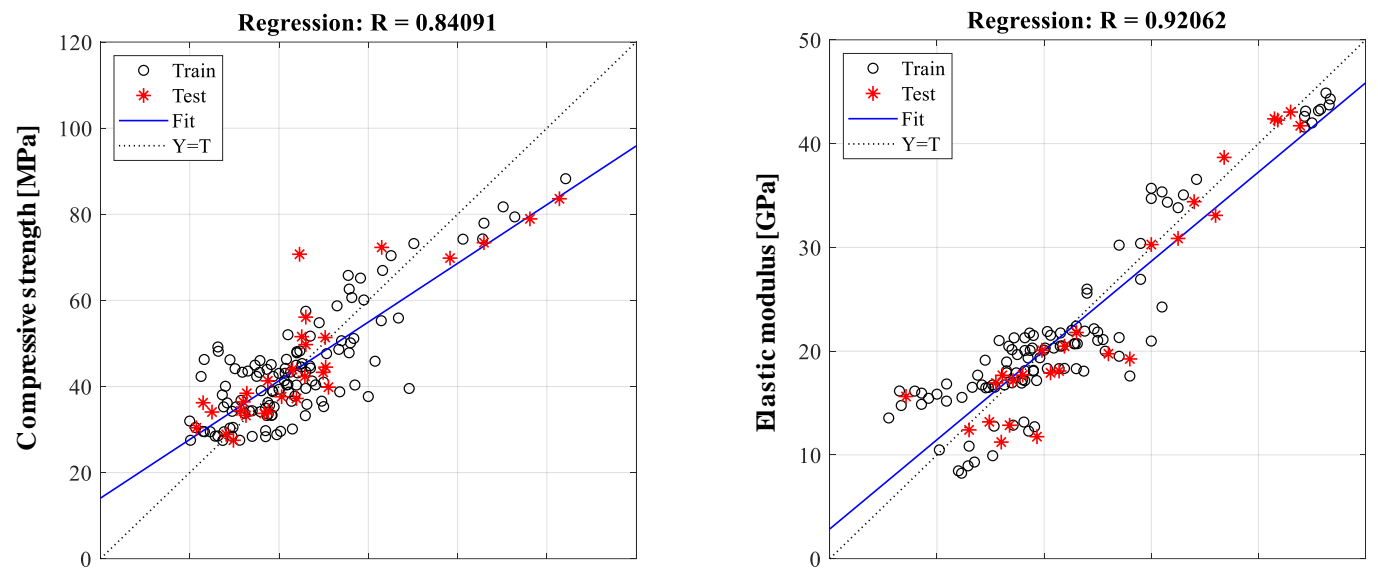

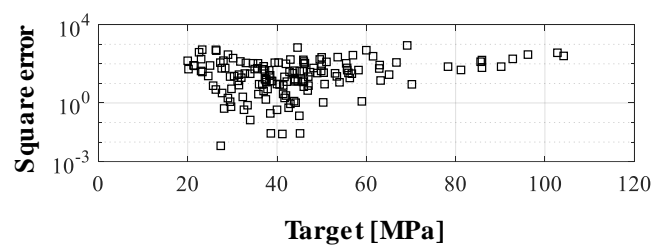

(a)

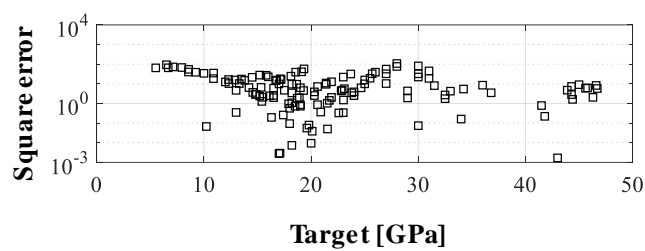

(b)

Figure 5. Prediction results from multiple linear regression (MLR)-based analysis: (a) compressive strength and (b) elastic modulus.
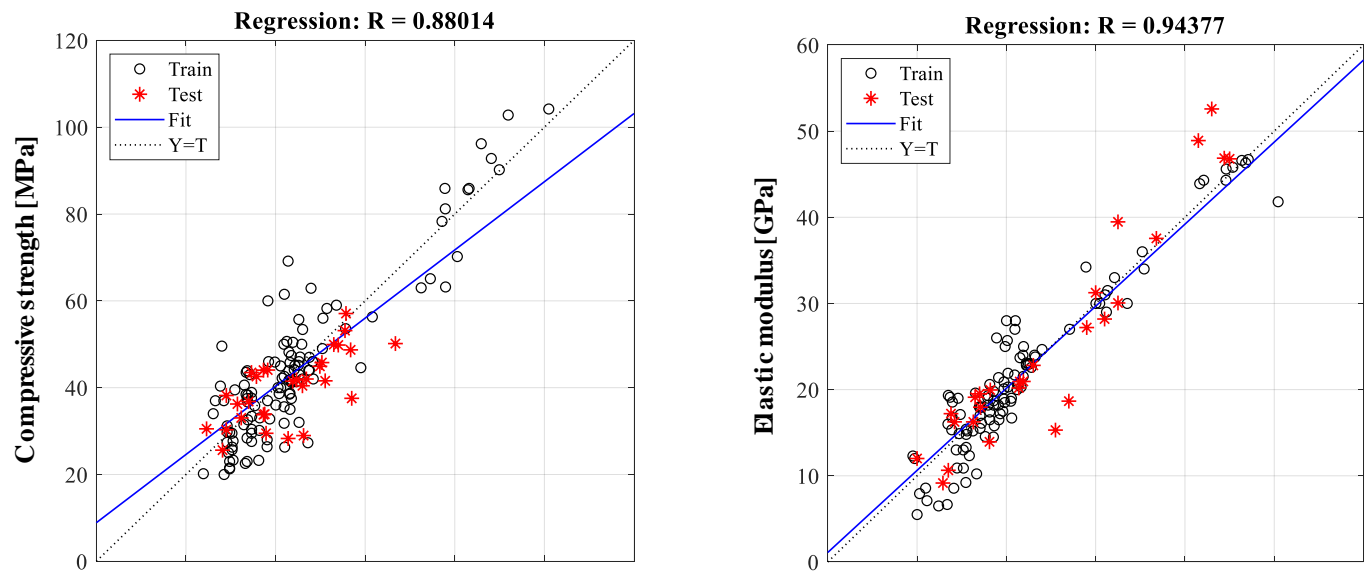

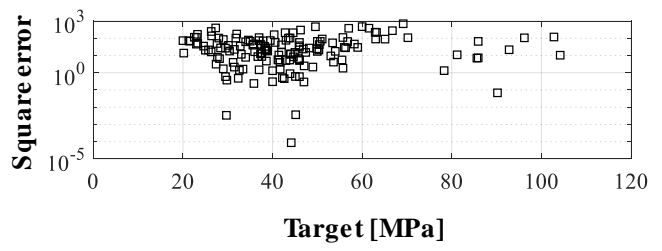

(a)

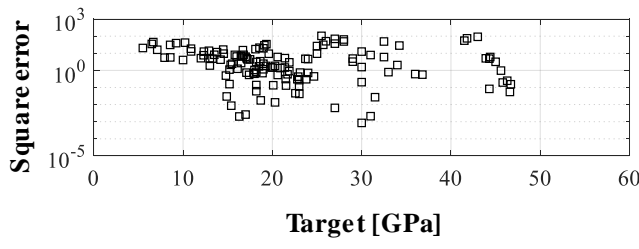

(b)

Figure 6. Prediction results from multiple nonlinear regression (MNLR)-based analysis: (a) compressive strength and (b) elastic modulus. 
The prediction accuracies obtained from ANN, MLR, and MNLR models are summarized in Table 6 in terms of the scale-independent MAE value. Compared to averaged MLR and MNLR models from 10 times analyses, the ANN-based prediction shows the highest accuracy with $M A E$ of $14.5 \%$ and $8.5 \%$ for the compressive strength and elastic modulus, respectively. High averaged $M A E$ values from linear and nonlinear regression models among 10 times repetitions show their wide range variations for predicting mechanical properties of LWAC. These variations in prediction accuracies indicate that used statistical models would not provide the reliable prediction results for LWAC. Thus, the ANN-based prediction model is shown to be suitable for characterizing the complex and nonlinear relationship between the concrete component materials and mechanical characteristics of LWAC.

Table 6. Prediction accuracies of ANN, MLR, and MNLR models.

\begin{tabular}{ccccc}
\hline \multirow{2}{*}{$\begin{array}{c}\text { Prediction Accuracy } \\
(\boldsymbol{M} A \boldsymbol{E})\end{array}$} & \multicolumn{2}{c}{ Compressive Strength } & \multicolumn{2}{c}{ Elastic Modulus } \\
\cline { 2 - 5 } & Training & Test & Training & Test \\
\hline ANN model & $9.6 \%$ & $14.5 \%$ & $6.9 \%$ & $8.5 \%$ \\
Linear regression & $17.0 \%$ & $19.7 \%$ & $19.0 \%$ & $21.4 \%$ \\
Nonlinear regression & $14.3 \%$ & $19.9 \%$ & $13.7 \%$ & $20.1 \%$ \\
\hline
\end{tabular}

\section{Conclusions}

This study presents the ANN-based prediction model for the compressive strength and elastic modulus of LWAC. The ANN model considers the complex and nonlinear relation between the mechanical properties and the concrete components of binders, NWAs, and LWAs. The database for the ANN model was constructed by collecting experimental data of various mix proportions, material properties, and mechanical properties of LWAC from the literature. Suitable input parameters and the optimal ANN architecture in terms of the number of hidden layers and neurons were determined to obtain a better prediction accuracy. To enhance the reliability of the ANN model, the five-fold cross validation was applied to all training and validation processes. The scaled conjugate gradient back-propagation algorithm was applied to obtain the optimal weight and bias values in the ANN model during the training stage. Subsequently, the prediction accuracy of the ANN model was evaluated. In comparison to previous studies using the ANN-based prediction model for NWAC, the ANN model used in this study showed acceptable prediction accuracy with respect to the compressive strength and elastic modulus of LWAC. Furthermore, a comparative analysis showed that the highest prediction accuracy is obtained by the ANN model compared to the use of statistical linear and nonlinear regression models.

Author Contributions: Conceptualization, J.Y.Y., H.K., and S.-H.S.; Methodology, J.Y.Y. and H.K.; Writing一original draft, J.Y.Y.; Writing-review and editing, S.-H.S. and Y.-J.L.

Funding: This research was funded by a grant (19CTAP-C143249-02) from Technology Advancement Research Program (TARP), funded by Ministry of Land, Infrastructure and Transport of the Korean government.

Conflicts of Interest: The authors declare that they have no conflict of interest. 


\section{Appendix A}

Table A1. Data sources.

\begin{tabular}{|c|c|c|c|c|c|c|c|c|c|c|c|c|c|c|c|c|}
\hline \multirow{2}{*}{ Literatures } & \multicolumn{9}{|c|}{ Mix Proportion $\left[\mathrm{kg} / \mathrm{m}^{3}\right]$} & \multicolumn{4}{|c|}{ Volume Fraction } & \multirow{2}{*}{$\begin{array}{l}\text { Density } \\
{\left[\mathrm{kg} / \mathrm{m}^{3}\right]}\end{array}$} & \multirow{2}{*}{$\begin{array}{c}\sigma_{28} \\
{[\mathrm{MPa}]}\end{array}$} & \multirow{2}{*}{$\begin{array}{c}\mathrm{E}_{28} \\
{[\mathrm{GPa}]}\end{array}$} \\
\hline & $\mathbf{w} / \mathbf{b}$ & W & $\mathrm{C}$ & FA & SF & CNWA & CLWA & FNWA & FLWA & CNWA & CLWA & FNWA & FLWA & & & \\
\hline \multirow{9}{*}{ Kim et al., 2010. [8] } & 0.38 & 175 & 460 & 0 & 0 & 810 & 0 & 861 & 0 & 0.30 & 0 & 0.34 & 0 & 2300 & 47 & 37.0 \\
\hline & 0.38 & 175 & 460 & 0 & 0 & 608 & 117 & 861 & 0 & 0.22 & 0.07 & 0.34 & 0 & 2280 & 44 & 29.0 \\
\hline & 0.38 & 175 & 460 & 0 & 0 & 405 & 234 & 861 & 0 & 0.15 & 0.15 & 0.34 & 0 & 2220 & 43 & 30.0 \\
\hline & 0.38 & 175 & 460 & 0 & 0 & 203 & 352 & 861 & 0 & 0.07 & 0.22 & 0.34 & 0 & 2200 & 42 & 33.0 \\
\hline & 0.38 & 175 & 460 & 0 & 0 & 0 & 469 & 861 & 0 & 0 & 0.30 & 0.34 & 0 & 2150 & 32 & 30.0 \\
\hline & 0.38 & 175 & 460 & 0 & 0 & 604 & 154 & 861 & 0 & 0.22 & 0.07 & 0.34 & 0 & 2280 & 44 & 31.0 \\
\hline & 0.38 & 175 & 460 & 0 & 0 & 402 & 308 & 861 & 0 & 0.15 & 0.15 & 0.34 & 0 & 2150 & 40 & 26.0 \\
\hline & 0.38 & 175 & 460 & 0 & 0 & 201 & 463 & 861 & 0 & 0.07 & 0.22 & 0.34 & 0 & 2100 & 40 & 24.0 \\
\hline & 0.38 & 175 & 460 & 0 & 0 & 0 & 617 & 861 & 0 & 0 & 0.30 & 0.34 & 0 & 2000 & 37 & 25.0 \\
\hline \multirow{5}{*}{$\begin{array}{c}\text { Bogas and Gomes } \\
\text { 2013. [30] }\end{array}$} & 0.50 & 225 & 450 & 0 & 0 & 0 & 374 & 676 & 0 & 0 & 0.35 & 0.26 & 0 & 1763 & 35 & - \\
\hline & 0.50 & 225 & 450 & 0 & 0 & 0 & 303 & 676 & 0 & 0 & 0.35 & 0.26 & 0 & 1686 & 27 & - \\
\hline & 0.35 & 158 & 450 & 0 & 0 & 0 & 374 & 847 & 0 & 0 & 0.35 & 0.32 & 0 & 1897 & 49 & - \\
\hline & 0.35 & 158 & 450 & 0 & 0 & 0 & 452 & 833 & 0 & 0 & 0.35 & 0.32 & 0 & 1942 & 66 & - \\
\hline & 0.35 & 158 & 450 & 0 & 0 & 0 & 247 & 846 & 0 & 0 & 0.35 & 0.32 & 0 & 1776 & 31 & - \\
\hline \multirow{2}{*}{$\begin{array}{c}\text { Bogas et al., } 2015 . \\
\text { [31] }\end{array}$} & 0.55 & 193 & 350 & 0 & 0 & 0 & 382 & 825 & 0 & 0 & 0.35 & 0.32 & 0 & 1897 & 38 & - \\
\hline & 0.55 & 193 & 350 & 0 & 0 & 0 & 208 & 825 & 0 & 0 & 0.35 & 0.32 & 0 & 1710 & 19 & - \\
\hline \multirow{13}{*}{$\begin{array}{c}\text { Nguyen et al., } 2014 . \\
\text { [4] }\end{array}$} & 0.45 & 190 & 426 & 0 & 0 & 0 & 445 & 554 & 0 & 0 & 0.45 & 0.23 & 0 & 1440 & 38 & 19.3 \\
\hline & 0.45 & 190 & 426 & 0 & 0 & 0 & 445 & 277 & 213 & 0 & 0.45 & 0.11 & 0.11 & 1380 & 36 & 18.6 \\
\hline & 0.45 & 190 & 426 & 0 & 0 & 0 & 445 & 0 & 427 & 0 & 0.45 & 0 & 0.22 & 1320 & 34 & 17.3 \\
\hline & 0.45 & 190 & 426 & 0 & 0 & 0 & 626 & 554 & 0 & 0 & 0.45 & 0.23 & 0 & 1490 & 35 & 19.1 \\
\hline & 0.45 & 190 & 426 & 0 & 0 & 0 & 626 & 277 & 177 & 0 & 0.45 & 0.11 & 0.11 & 1410 & 33 & 17.0 \\
\hline & 0.45 & 190 & 426 & 0 & 0 & 0 & 626 & 0 & 354 & 0 & 0.45 & 0 & 0.22 & 1340 & 31 & 15.3 \\
\hline & 0.45 & 190 & 426 & 0 & 0 & 0 & 558 & 554 & 0 & 0 & 0.45 & 0.23 & 0 & 1410 & 31 & 16.3 \\
\hline & 0.45 & 190 & 426 & 0 & 0 & 0 & 558 & 277 & 189 & 0 & 0.45 & 0.11 & 0.11 & 1290 & 26 & 13.6 \\
\hline & 0.45 & 190 & 426 & 0 & 0 & 0 & 558 & 0 & 379 & 0 & 0.45 & 0 & 0.23 & 1170 & 22 & 11.1 \\
\hline & 0.45 & 190 & 426 & 0 & 0 & 0 & 673 & 554 & 0 & 0 & 0.45 & 0.23 & 0 & 1520 & 40 & 18.2 \\
\hline & 0.45 & 190 & 426 & 0 & 0 & 0 & 673 & 277 & 189 & 0 & 0.45 & 0.11 & 0.11 & 1400 & 35 & 15.7 \\
\hline & 0.45 & 190 & 426 & 0 & 0 & 0 & 673 & 0 & 379 & 0 & 0.45 & 0 & 0.23 & 1280 & 31 & 13.6 \\
\hline & 0.45 & 190 & 426 & 0 & 0 & 1105 & 0 & 554 & 0 & 0.45 & 0 & 0.23 & 0 & 2030 & 52 & 32.7 \\
\hline
\end{tabular}


Table A1. Cont.

\begin{tabular}{|c|c|c|c|c|c|c|c|c|c|c|c|c|c|c|c|c|}
\hline \multirow{2}{*}{ Literatures } & \multicolumn{9}{|c|}{ Mix Proportion $\left[\mathrm{kg} / \mathrm{m}^{3}\right]$} & \multicolumn{4}{|c|}{ Volume Fraction } & \multirow{2}{*}{$\begin{array}{l}\text { Density } \\
{\left[\mathrm{kg} / \mathrm{m}^{3}\right]}\end{array}$} & \multirow{2}{*}{$\begin{array}{c}\sigma_{28} \\
{[\mathrm{MPa}]}\end{array}$} & \multirow{2}{*}{$\begin{array}{c}\mathrm{E}_{28} \\
{[\mathrm{GPa}]}\end{array}$} \\
\hline & $\mathbf{w} / \mathbf{b}$ & $\mathbf{W}$ & $\mathrm{C}$ & FA & SF & CNWA & CLWA & FNWA & FLWA & CNWA & CLWA & FNWA & FLWA & & & \\
\hline \multirow{9}{*}{ Choi et al., 2006. [33] } & 0.38 & 175 & 460 & 0 & 0 & 810 & 0 & 861 & 0 & 0.31 & 0 & 0.34 & 0 & 2306 & 49 & 34.0 \\
\hline & 0.38 & 175 & 460 & 0 & 0 & 608 & 117 & 861 & 0 & 0.23 & 0.07 & 0.34 & 0 & 2221 & 46 & 27.0 \\
\hline & 0.38 & 175 & 460 & 0 & 0 & 405 & 234 & 861 & 0 & 0.16 & 0.15 & 0.34 & 0 & 2135 & 45 & 24.0 \\
\hline & 0.38 & 175 & 460 & 0 & 0 & 203 & 352 & 861 & 0 & 0.08 & 0.22 & 0.34 & 0 & 2051 & 46 & 25.0 \\
\hline & 0.38 & 175 & 460 & 0 & 0 & 0 & 469 & 861 & 0 & 0 & 0.30 & 0.34 & 0 & 1965 & 34 & 28.0 \\
\hline & 0.38 & 175 & 460 & 0 & 0 & 810 & 0 & 645 & 158 & 0.31 & 0 & 0.25 & 0.10 & 2248 & 46 & 30.0 \\
\hline & 0.38 & 175 & 460 & 0 & 0 & 810 & 0 & 430 & 316 & 0.31 & 0 & 0.17 & 0.20 & 2191 & 46 & 33.0 \\
\hline & 0.38 & 175 & 460 & 0 & 0 & 810 & 0 & 215 & 473 & 0.31 & 0 & 0.08 & 0.29 & 2133 & 53 & 31.0 \\
\hline & 0.38 & 175 & 460 & 0 & 0 & 810 & 0 & 0 & 631 & 0.31 & 0 & 0 & 0.39 & 2076 & 59 & 30.0 \\
\hline \multirow{12}{*}{$\begin{array}{l}\text { Yang and Huang } \\
\text { 1998. [34] }\end{array}$} & 0.28 & 178 & 626 & 0 & 0 & 0 & 292 & 1096 & 0 & 0 & 0.18 & 0.42 & 0 & 2192 & 41 & 23.0 \\
\hline & 0.28 & 178 & 626 & 0 & 0 & 0 & 299 & 1096 & 0 & 0 & 0.18 & 0.42 & 0 & 2199 & 44 & 23.8 \\
\hline & 0.28 & 178 & 626 & 0 & 0 & 0 & 311 & 1096 & 0 & 0 & 0.18 & 0.42 & 0 & 2211 & 50 & 24.7 \\
\hline & 0.28 & 178 & 626 & 0 & 0 & 0 & 389 & 939 & 0 & 0 & 0.24 & 0.36 & 0 & 2132 & 37 & 20.6 \\
\hline & 0.28 & 178 & 626 & 0 & 0 & 0 & 399 & 939 & 0 & 0 & 0.24 & 0.36 & 0 & 2142 & 41 & 21.5 \\
\hline & 0.28 & 178 & 626 & 0 & 0 & 0 & 415 & 939 & 0 & 0 & 0.24 & 0.36 & 0 & 2158 & 47 & 22.6 \\
\hline & 0.28 & 178 & 626 & 0 & 0 & 0 & 486 & 783 & 0 & 0 & 0.30 & 0.30 & 0 & 2073 & 35 & 18.2 \\
\hline & 0.28 & 178 & 626 & 0 & 0 & 0 & 498 & 783 & 0 & 0 & 0.30 & 0.30 & 0 & 2085 & 38 & 19.0 \\
\hline & 0.28 & 178 & 626 & 0 & 0 & 0 & 519 & 783 & 0 & 0 & 0.30 & 0.30 & 0 & 2106 & 45 & 20.3 \\
\hline & 0.28 & 178 & 626 & 0 & 0 & 0 & 583 & 626 & 0 & 0 & 0.36 & 0.24 & 0 & 2013 & 62 & 15.8 \\
\hline & 0.28 & 178 & 626 & 0 & 0 & 0 & 598 & 626 & 0 & 0 & 0.36 & 0.24 & 0 & 2028 & 36 & 17.2 \\
\hline & 0.28 & 178 & 626 & 0 & 0 & 0 & 623 & 626 & 0 & 0 & 0.36 & 0.24 & 0 & 2053 & 42 & 18.7 \\
\hline \multirow{4}{*}{$\begin{array}{c}\text { Kockal and Ozturan } \\
\text { 2011. [10] }\end{array}$} & 0.26 & 158 & 551 & 0 & 55 & 0 & 592 & 636 & 0 & 0 & 0.37 & 0.24 & 0 & 1860 & 42 & 19.6 \\
\hline & 0.26 & 157 & 548 & 0 & 55 & 0 & 567 & 633 & 0 & 0 & 0.36 & 0.24 & 0 & 1915 & 54 & 26.0 \\
\hline & 0.26 & 157 & 549 & 0 & 55 & 0 & 580 & 634 & 0 & 0 & 0.36 & 0.24 & 0 & 1943 & 56 & 25.7 \\
\hline & 0.26 & 158 & 551 & 0 & 55 & 981 & 0 & 636 & 0 & 0.36 & 0 & 0.24 & 0 & 2316 & 63 & 36.8 \\
\hline \multirow{12}{*}{$\begin{array}{c}\text { Gesoglu et al., } 2007 . \\
\text { [36] }\end{array}$} & 0.35 & 192 & 550 & 0 & 0 & 0 & 487 & 862 & 0 & 0 & 0.27 & 0.33 & 0 & 2101 & 36 & 20.0 \\
\hline & 0.35 & 192 & 547 & 0 & 0 & 0 & 646 & 624 & 0 & 0 & 0.36 & 0.24 & 0 & 2015 & 28 & 18.0 \\
\hline & 0.35 & 191 & 547 & 0 & 0 & 0 & 465 & 858 & 0 & 0 & 0.27 & 0.33 & 0 & 2070 & 60 & 29.0 \\
\hline & 0.35 & 193 & 550 & 0 & 0 & 0 & 624 & 628 & 0 & 0 & 0.36 & 0.24 & 0 & 2000 & 57 & 28.0 \\
\hline & 0.35 & 193 & 550 & 0 & 0 & 0 & 506 & 863 & 0 & 0 & 0.28 & 0.33 & 0 & 2122 & 50 & 25.0 \\
\hline & 0.35 & 193 & 550 & 0 & 0 & 0 & 675 & 627 & 0 & 0 & 0.38 & 0.24 & 0 & 2056 & 46 & 27.0 \\
\hline & 0.55 & 220 & 399 & 0 & 0 & 0 & 509 & 902 & 0 & 0 & 0.29 & 0.35 & 0 & 2032 & 23 & 17.0 \\
\hline & 0.55 & 220 & 401 & 0 & 0 & 0 & 681 & 658 & 0 & 0 & 0.38 & 0.25 & 0 & 1960 & 20 & 14.0 \\
\hline & 0.55 & 221 & 403 & 0 & 0 & 0 & 475 & 908 & 0 & 0 & 0.28 & 0.35 & 0 & 2010 & 37 & 19.0 \\
\hline & 0.55 & 220 & 399 & 0 & 0 & 0 & 631 & 657 & 0 & 0 & 0.37 & 0.25 & 0 & 1907 & 34 & 18.0 \\
\hline & 0.55 & 218 & 397 & 0 & 0 & 0 & 525 & 895 & 0 & 0 & 0.29 & 0.34 & 0 & 2038 & 29 & 19.0 \\
\hline & 0.55 & 219 & 399 & 0 & 0 & 0 & 706 & 657 & 0 & 0 & 0.39 & 0.25 & 0 & 1981 & 25 & 17.0 \\
\hline
\end{tabular}


Table A1. Cont.

\begin{tabular}{|c|c|c|c|c|c|c|c|c|c|c|c|c|c|c|c|c|}
\hline \multirow{2}{*}{ Literatures } & \multicolumn{9}{|c|}{ Mix Proportion $\left[\mathrm{kg} / \mathrm{m}^{3}\right]$} & \multicolumn{4}{|c|}{ Volume Fraction } & \multirow{2}{*}{$\begin{array}{l}\text { Density } \\
{\left[\mathrm{kg} / \mathrm{m}^{3}\right]}\end{array}$} & \multirow{2}{*}{$\begin{array}{c}\sigma_{28} \\
{[\mathrm{MPa}]}\end{array}$} & \multirow{2}{*}{$\begin{array}{c}\mathrm{E}_{28} \\
\text { [GPa] }\end{array}$} \\
\hline & $w / b$ & $\mathbf{W}$ & $\mathrm{C}$ & FA & SF & CNWA & CLWA & FNWA & FLWA & CNWA & CLWA & FNWA & FLWA & & & \\
\hline \multirow{36}{*}{ Chi et al., 2003. [32] } & 0.28 & 171 & 602 & 0 & 0 & 0 & 297 & 1096 & 0 & 0 & 0.18 & 0.42 & 0 & 2166 & 42 & 22.9 \\
\hline & 0.28 & 171 & 602 & 0 & 0 & 0 & 396 & 939 & 0 & 0 & 0.24 & 0.36 & 0 & 2108 & 38 & 21.5 \\
\hline & 0.28 & 171 & 602 & 0 & 0 & 0 & 495 & 783 & 0 & 0 & 0.30 & 0.30 & 0 & 2051 & 35 & 20.1 \\
\hline & 0.28 & 171 & 602 & 0 & 0 & 0 & 594 & 626 & 0 & 0 & 0.36 & 0.24 & 0 & 1993 & 32 & 18.7 \\
\hline & 0.39 & 202 & 517 & 0 & 0 & 0 & 297 & 1096 & 0 & 0 & 0.18 & 0.42 & 0 & 2112 & 33 & 20.3 \\
\hline & 0.39 & 202 & 517 & 0 & 0 & 0 & 396 & 939 & 0 & 0 & 0.24 & 0.36 & 0 & 2054 & 30 & 16.5 \\
\hline & 0.39 & 202 & 517 & 0 & 0 & 0 & 495 & 783 & 0 & 0 & 0.30 & 0.30 & 0 & 1997 & 28 & 16.5 \\
\hline & 0.39 & 202 & 517 & 0 & 0 & 0 & 594 & 626 & 0 & 0 & 0.36 & 0.24 & 0 & 1939 & 23 & 13.8 \\
\hline & 0.50 & 226 & 453 & 0 & 0 & 0 & 297 & 1096 & 0 & 0 & 0.18 & 0.42 & 0 & 2072 & 30 & 18.2 \\
\hline & 0.50 & 226 & 453 & 0 & 0 & 0 & 396 & 939 & 0 & 0 & 0.24 & 0.36 & 0 & 2014 & 26 & 15.5 \\
\hline & 0.50 & 226 & 453 & 0 & 0 & 0 & 495 & 783 & 0 & 0 & 0.30 & 0.30 & 0 & 1957 & 23 & 14.2 \\
\hline & 0.50 & 226 & 453 & 0 & 0 & 0 & 594 & 626 & 0 & 0 & 0.36 & 0.24 & 0 & 1899 & 21 & 13.3 \\
\hline & 0.28 & 171 & 602 & 0 & 0 & 0 & 304 & 1096 & 0 & 0 & 0.18 & 0.42 & 0 & 2166 & 44 & 22.8 \\
\hline & 0.28 & 171 & 602 & 0 & 0 & 0 & 406 & 939 & 0 & 0 & 0.24 & 0.36 & 0 & 2108 & 41 & 21.7 \\
\hline & 0.28 & 171 & 602 & 0 & 0 & 0 & 507 & 783 & 0 & 0 & 0.30 & 0.30 & 0 & 2051 & 39 & 18.9 \\
\hline & 0.28 & 171 & 602 & 0 & 0 & 0 & 608 & 626 & 0 & 0 & 0.36 & 0.24 & 0 & 1993 & 36 & 18.2 \\
\hline & 0.39 & 202 & 517 & 0 & 0 & 0 & 304 & 1096 & 0 & 0 & 0.18 & 0.42 & 0 & 2112 & 37 & 21.4 \\
\hline & 0.39 & 202 & 517 & 0 & 0 & 0 & 406 & 939 & 0 & 0 & 0.24 & 0.36 & 0 & 2054 & 33 & 18.2 \\
\hline & 0.39 & 202 & 517 & 0 & 0 & 0 & 507 & 783 & 0 & 0 & 0.30 & 0.30 & 0 & 1997 & 30 & 17.4 \\
\hline & 0.39 & 202 & 517 & 0 & 0 & 0 & 608 & 626 & 0 & 0 & 0.36 & 0.24 & 0 & 1939 & 28 & 16.1 \\
\hline & 0.50 & 226 & 453 & 0 & 0 & 0 & 304 & 1096 & 0 & 0 & 0.18 & 0.42 & 0 & 2072 & 27 & 17.1 \\
\hline & 0.50 & 226 & 453 & 0 & 0 & 0 & 406 & 939 & 0 & 0 & 0.24 & 0.36 & 0 & 2014 & 26 & 17.0 \\
\hline & 0.50 & 226 & 453 & 0 & 0 & 0 & 507 & 783 & 0 & 0 & 0.30 & 0.30 & 0 & 1957 & 25 & 15.2 \\
\hline & 0.50 & 226 & 453 & 0 & 0 & 0 & 608 & 626 & 0 & 0 & 0.36 & 0.24 & 0 & 1899 & 22 & 14.8 \\
\hline & 0.28 & 171 & 602 & 0 & 0 & 0 & 317 & 1096 & 0 & 0 & 0.18 & 0.42 & 0 & 2166 & 48 & 23.1 \\
\hline & 0.28 & 171 & 602 & 0 & 0 & 0 & 422 & 939 & 0 & 0 & 0.24 & 0.36 & 0 & 2108 & 47 & 21.9 \\
\hline & 0.28 & 171 & 602 & 0 & 0 & 0 & 528 & 783 & 0 & 0 & 0.30 & 0.30 & 0 & 2051 & 46 & 20.9 \\
\hline & 0.28 & 171 & 602 & 0 & 0 & 0 & 634 & 626 & 0 & 0 & 0.36 & 0.24 & 0 & 1993 & 43 & 19.8 \\
\hline & 0.39 & 202 & 517 & 0 & 0 & 0 & 317 & 1096 & 0 & 0 & 0.18 & 0.42 & 0 & 2112 & 38 & 21.9 \\
\hline & 0.39 & 202 & 517 & 0 & 0 & 0 & 422 & 939 & 0 & 0 & 0.24 & 0.36 & 0 & 2054 & 38 & 21.4 \\
\hline & 0.39 & 202 & 517 & 0 & 0 & 0 & 528 & 783 & 0 & 0 & 0.30 & 0.30 & 0 & 1997 & 39 & 20.6 \\
\hline & 0.39 & 202 & 517 & 0 & 0 & 0 & 634 & 626 & 0 & 0 & 0.36 & 0.24 & 0 & 1939 & 38 & 18.0 \\
\hline & 0.50 & 226 & 453 & 0 & 0 & 0 & 317 & 1096 & 0 & 0 & 0.18 & 0.42 & 0 & 2072 & 31 & 19.3 \\
\hline & 0.50 & 226 & 453 & 0 & 0 & 0 & 422 & 939 & 0 & 0 & 0.24 & 0.36 & 0 & 2014 & 30 & 17.9 \\
\hline & 0.50 & 226 & 453 & 0 & 0 & 0 & 528 & 783 & 0 & 0 & 0.30 & 0.30 & 0 & 1957 & 28 & 16.3 \\
\hline & 0.50 & 226 & 453 & 0 & 0 & 0 & 634 & 626 & 0 & 0 & 0.36 & 0.24 & 0 & 1899 & 30 & 15.4 \\
\hline
\end{tabular}


Table A1. Cont.

\begin{tabular}{|c|c|c|c|c|c|c|c|c|c|c|c|c|c|c|c|c|}
\hline \multirow{2}{*}{ Literatures } & \multicolumn{9}{|c|}{ Mix Proportion $\left[\mathrm{kg} / \mathrm{m}^{3}\right]$} & \multicolumn{4}{|c|}{ Volume Fraction } & \multirow{2}{*}{$\begin{array}{l}\text { Density } \\
{\left[\mathrm{kg} / \mathrm{m}^{3}\right]}\end{array}$} & \multirow{2}{*}{$\begin{array}{c}\sigma_{28} \\
{[\mathrm{MPa}]}\end{array}$} & \multirow{2}{*}{$\begin{array}{c}E_{28} \\
\text { [GPa] }\end{array}$} \\
\hline & $\mathbf{w} / \mathbf{b}$ & $\mathbf{W}$ & $\mathrm{C}$ & FA & SF & CNWA & CLWA & FNWA & FLWA & CNWA & CLWA & FNWA & FLWA & & & \\
\hline \multirow{7}{*}{ Kayali, 2008. [35] } & 0.27 & 172 & 300 & 300 & 40 & 1001 & 0 & 288 & 0 & 0.37 & 0 & 0.12 & 0 & 2134 & 56 & 32.5 \\
\hline & 0.23 & 150 & 300 & 300 & 40 & 0 & 898 & 0 & 233 & 0 & 0.52 & 0 & 0.14 & 1540 & 45 & 16.7 \\
\hline & 0.30 & 193 & 300 & 300 & 40 & 0 & 766 & 0 & 162 & 0 & 0.45 & 0 & 0.10 & 1747 & 63 & 23.7 \\
\hline & 0.36 & 207 & 370 & 142 & 57 & 894 & 0 & 626 & 0 & 0.33 & 0 & 0.24 & 0 & 2260 & 58 & 32.5 \\
\hline & 0.36 & 207 & 370 & 142 & 57 & 0 & 481 & 0 & 476 & 0 & 0.28 & 0 & 0.28 & 1770 & 53 & 19.0 \\
\hline & 0.36 & 207 & 370 & 142 & 57 & 820 & 0 & 626 & 0 & 0.33 & 0 & 0.24 & 0 & 2280 & 56 & 31.5 \\
\hline & 0.36 & 207 & 370 & 142 & 57 & 0 & 440 & 0 & 511 & 0 & 0.28 & 0 & 0.32 & 1780 & 67 & 25.5 \\
\hline \multirow{9}{*}{$\begin{array}{c}\text { Guneyisi et al., } 2012 . \\
\text { [29] }\end{array}$} & 0.35 & 193 & 550 & 0 & 0 & 0 & 688 & 688 & 0 & 0 & 0.36 & 0.27 & 0 & 2124 & 48 & - \\
\hline & 0.35 & 193 & 468 & 83 & 0 & 0 & 677 & 677 & 0 & 0 & 0.35 & 0.26 & 0 & 2101 & 45 & - \\
\hline & 0.35 & 193 & 385 & 165 & 0 & 0 & 665 & 665 & 0 & 0 & 0.35 & 0.26 & 0 & 2078 & 42 & - \\
\hline & 0.35 & 193 & 523 & 0 & 28 & 0 & 684 & 684 & 0 & 0 & 0.36 & 0.26 & 0 & 2117 & 53 & - \\
\hline & 0.35 & 193 & 495 & 0 & 55 & 0 & 680 & 680 & 0 & 0 & 0.35 & 0.26 & 0 & 2109 & 54 & - \\
\hline & 0.35 & 193 & 440 & 83 & 28 & 0 & 670 & 670 & 0 & 0 & 0.35 & 0.26 & 0 & 2090 & 48 & - \\
\hline & 0.35 & 193 & 413 & 83 & 55 & 0 & 669 & 668 & 0 & 0 & 0.35 & 0.26 & 0 & 2085 & 48 & - \\
\hline & 0.35 & 193 & 358 & 165 & 28 & 0 & 661 & 661 & 0 & 0 & 0.34 & 0.26 & 0 & 2070 & 43 & - \\
\hline & 0.35 & 193 & 330 & 165 & 55 & 0 & 657 & 657 & 0 & 0 & 0.34 & 0.25 & 0 & 2062 & 43 & - \\
\hline \multirow{5}{*}{$\begin{array}{l}\text { Rossignolo et al., } \\
\text { 2003. [2] }\end{array}$} & 0.34 & 263 & 710 & 0 & 71 & 0 & 447 & 192 & 0 & 0 & 0.34 & 0.07 & 0 & 1605 & 54 & 15.2 \\
\hline & 0.37 & 251 & 613 & 0 & 61 & 0 & 494 & 215 & 0 & 0 & 0.38 & 0.08 & 0 & 1573 & 50 & 13.5 \\
\hline & 0.41 & 245 & 544 & 0 & 54 & 0 & 533 & 228 & 0 & 0 & 0.41 & 0.09 & 0 & 1532 & 46 & 12.9 \\
\hline & 0.45 & 237 & 484 & 0 & 48 & 0 & 560 & 242 & 0 & 0 & 0.43 & 0.09 & 0 & 1482 & 43 & 12.3 \\
\hline & 0.49 & 238 & 440 & 0 & 44 & 0 & 585 & 250.8 & 0 & 0 & 0.45 & 0.10 & 0 & 1460 & 40 & 12.0 \\
\hline \multirow{6}{*}{$\begin{array}{c}\text { Aslam et al., } 2016 . \\
\text { [37] }\end{array}$} & 0.36 & 173 & 480 & 0 & 0 & 0 & 360 & 890 & 0 & 0 & 0.30 & 0.33 & 0 & 1790 & 36 & 7.9 \\
\hline & 0.36 & 173 & 480 & 0 & 0 & 0 & 375 & 890 & 0 & 0 & 0.30 & 0.33 & 0 & 1810 & 37 & 9.6 \\
\hline & 0.36 & 173 & 480 & 0 & 0 & 0 & 390 & 890 & 0 & 0 & 0.30 & 0.33 & 0 & 1850 & 42 & 10.2 \\
\hline & 0.36 & 173 & 480 & 0 & 0 & 0 & 405 & 890 & 0 & 0 & 0.29 & 0.33 & 0 & 1840 & 44 & 11.7 \\
\hline & 0.36 & 173 & 480 & 0 & 0 & 0 & 421 & 890 & 0 & 0 & 0.29 & 0.33 & 0 & 1860 & 43 & 13.0 \\
\hline & 0.36 & 173 & 480 & 0 & 0 & 0 & 436 & 890 & 0 & 0 & 0.29 & 0.33 & 0 & 1910 & 41 & 15.0 \\
\hline \multirow{7}{*}{$\begin{array}{l}\text { Alengaram et al., } \\
\text { 2011. [27] }\end{array}$} & 0.30 & 179 & 515 & 27 & 54 & 0 & 542 & 436 & 0 & 0 & 0.43 & 0.16 & 0 & 1677 & 30 & 7.1 \\
\hline & 0.32 & 187 & 510 & 25 & 50 & 0 & 535 & 430 & 0 & 0 & 0.42 & 0.16 & 0 & 1743 & 27 & 6.5 \\
\hline & 0.35 & 201 & 501 & 24 & 48 & 0 & 525 & 422 & 0 & 0 & 0.41 & 0.16 & 0 & 1643 & 26 & 5.5 \\
\hline & 0.35 & 189 & 465 & 25 & 50 & 0 & 392 & 784 & 0 & 0 & 0.31 & 0.29 & 0 & 1869 & 38 & 10.9 \\
\hline & 0.35 & 205 & 504 & 27 & 54 & 0 & 424 & 637 & 0 & 0 & 0.33 & 0.24 & 0 & 1810 & 35 & 10.0 \\
\hline & 0.35 & 216 & 532 & 28 & 56 & 0 & 448 & 560 & 0 & 0 & 0.35 & 0.21 & 0 & 1787 & 33 & 8.6 \\
\hline & 0.35 & 229 & 564 & 30 & 60 & 0 & 475 & 475 & 0 & 0 & 0.37 & 0.18 & 0 & 1759 & 30 & 7.9 \\
\hline
\end{tabular}


Table A1. Cont.

\begin{tabular}{|c|c|c|c|c|c|c|c|c|c|c|c|c|c|c|c|c|}
\hline \multirow{2}{*}{ Literatures } & \multicolumn{9}{|c|}{ Mix Proportion $\left[\mathrm{kg} / \mathrm{m}^{3}\right]$} & \multicolumn{4}{|c|}{ Volume Fraction } & \multirow{2}{*}{$\begin{array}{l}\text { Density } \\
{\left[\mathrm{kg} / \mathrm{m}^{3}\right]}\end{array}$} & \multirow{2}{*}{$\begin{array}{c}\sigma_{28} \\
{[\mathrm{MPa}]}\end{array}$} & \multirow{2}{*}{$\begin{array}{c}\mathrm{E}_{28} \\
{[\mathrm{GPa}]}\end{array}$} \\
\hline & $w / b$ & $\mathbf{W}$ & $\mathrm{C}$ & FA & SF & CNWA & CLWA & FNWA & FLWA & CNWA & CLWA & FNWA & FLWA & & & \\
\hline \multirow{13}{*}{ Wee et al., 1996. [28] } & 0.40 & 170 & 425 & 0 & 0 & 1083 & 0 & 722 & 0 & 0.42 & 0 & 0.28 & 0 & 2400 & 63 & 41.8 \\
\hline & 0.40 & 170 & 383 & 0 & 43 & 1083 & 0 & 722 & 0 & 0.42 & 0 & 0.28 & 0 & 2401 & 70 & 43.0 \\
\hline & 0.40 & 170 & 298 & 128 & 0 & 1083 & 0 & 722 & 0 & 0.42 & 0 & 0.28 & 0 & 2401 & 65 & 41.5 \\
\hline & 0.35 & 170 & 437 & 0 & 43 & 1046 & 0 & 698 & 0 & 0.40 & 0 & 0.27 & 0 & 2394 & 86 & 45.0 \\
\hline & 0.35 & 170 & 389 & 0 & 96 & 1046 & 0 & 698 & 0 & 0.40 & 0 & 0.27 & 0 & 2399 & 90 & 44.4 \\
\hline & 0.30 & 165 & 550 & 0 & 0 & 1045 & 0 & 640 & 0 & 0.40 & 0 & 0.25 & 0 & 2400 & 78 & 44.3 \\
\hline & 0.30 & 165 & 495 & 0 & 55 & 1046 & 0 & 640 & 0 & 0.40 & 0 & 0.25 & 0 & 2401 & 86 & 44.3 \\
\hline & 0.30 & 165 & 385 & 165 & 0 & 1045 & 0 & 640 & 0 & 0.40 & 0 & 0.25 & 0 & 2400 & 81 & 43.9 \\
\hline & 0.25 & 160 & 640 & 0 & 0 & 1043 & 0 & 587 & 0 & 0.40 & 0 & 0.23 & 0 & 2430 & 86 & 45.6 \\
\hline & 0.25 & 160 & 608 & 0 & 32 & 1043 & 0 & 587 & 0 & 0.40 & 0 & 0.23 & 0 & 2430 & 96 & 46.6 \\
\hline & 0.25 & 160 & 576 & 0 & 64 & 1043 & 0 & 587 & 0 & 0.40 & 0 & 0.23 & 0 & 2430 & 103 & 46.7 \\
\hline & 0.25 & 160 & 544 & 0 & 96 & 1043 & 0 & 587 & 0 & 0.40 & 0 & 0.23 & 0 & 2430 & 104 & 46.3 \\
\hline & 0.25 & 160 & 448 & 192 & 0 & 1043 & 0 & 587 & 0 & 0.40 & 0 & 0.23 & 0 & 2430 & 93 & 45.8 \\
\hline
\end{tabular}




\section{References}

1. Ke, Y.; Ortola, S.; Beaucour, A.L.; Dumontet, H. Identification of microstructural characteristics in lightweight aggregate concretes by micromechanical modelling including the interfacial transition zone (ITZ). Cem. Concr. Res. 2010, 40, 1590-1600. [CrossRef]

2. Rossignolo, J.A.; Agnesini, M.V.C.; Morais, J.A. Properties of high-performance LWAC for precast structures with Brazilian lightweight aggregates. Cem. Concr. Compos. 2003, 25, 77-82. [CrossRef]

3. Elsharief, A.; Cohen, M.D.; Olek, J. Influence of lightweight aggregate on the microstructure and durability of mortar. Cem. Concr. Res. 2005, 35, 1368-1376. [CrossRef]

4. Nguyen, L.H.; Beaucour, A.L.; Ortola, S.; Noumowé, A. Influence of the volume fraction and the nature of fine lightweight aggregates on the thermal and mechanical properties of structural concrete. Constr. Build. Mater. 2014, 51, 121-132. [CrossRef]

5. Yoon, J.Y.; Lee, J.Y.; Kim, J.H. Use of raw-state bottom ash for aggregates in construction materials. J. Mater. Cycles Waste Manag. 2019, 21, 838-849. [CrossRef]

6. ASTM C330/C330M-17a. Standard Specification for Lightweight Aggregates for Structural Concrete; ASTM International: West Conshohocken, PA, USA, 2017.

7. Guide for Structural Lightweight-Aggregate Concrete; ACI 213R-14; American Concrete Institute: Farmington Hills, MI, USA, 2014.

8. Kim, Y.J.; Choi, Y.W.; Lachemi, M. Characteristics of self-consolidating concrete using two types of lightweight coarse aggregates. Constr. Build. Mater. 2010, 24, 11-16. [CrossRef]

9. Bogas, J.A.; Gomes, A.; Pereira, M.F.C. Self-compacting lightweight concrete produced with expanded clay aggregate. Constr. Build. Mater. 2012, 35, 1013-1022. [CrossRef]

10. Kockal, N.U.; Ozturan, T. Strength and elastic properties of structural lightweight concretes. Mater. Des. 2011, 32, 2396-2403. [CrossRef]

11. Kanadasan, J.; Razak, H.A. Mix design for self-compacting palm oil clinker concrete based on particle packing. Mater. Des. 2014, 56, 9-19. [CrossRef]

12. Nepomuceno, M.C.S.; Pereira-de-Oliveira, L.A.; Pereira, S.F. Mix design of structural lightweight self-compacting concrete incorporating coarse lightweight expanded clay aggregates. Constr. Build. Mater. 2018, 166, 373-385. [CrossRef]

13. Lippmann, R. An introduction to computing with neural nets. IEEE ASSP Mag. 1987, 4, 4-22. [CrossRef]

14. Ni, H.G.; Wang, J.Z. Prediction of compressive strength of concrete by neural networks. Cem. Concr. Res. 2000, 30, 1245-1250. [CrossRef]

15. Belalia Douma, O.; Boukhatem, B.; Ghrici, M.; Tagnit-Hamou, A. Prediction of properties of self-compacting concrete containing fly ash using artificial neural network. Neural Comput. Appl. 2017, 28,707-718. [CrossRef]

16. Öztaş, A.; Pala, M.; Özbay, E.; Kanca, E.; Çag`lar, N.; Bhatti, M.A. Predicting the compressive strength and slump of high strength concrete using neural network. Constr. Build. Mater. 2006, 20, 769-775. [CrossRef]

17. Alshihri, M.M.; Azmy, A.M.; El-Bisy, M.S. Neural networks for predicting compressive strength of structural light weight concrete. Constr. Build. Mater. 2009, 23, 2214-2219. [CrossRef]

18. Tavakkol, S.; Alapour, F.; Kazemian, A.; Hasaninejad, A.; Ghanbari, A.; Ramezanianpour, A.A. Prediction of lightweight concrete strength by categorized regression, MLR and ANN. Comput. Concr. 2013, 12, 151-167. [CrossRef]

19. Davraz, M.; Kilinçarslan, Ş.; Ceylan, H. Predicting the Poisson Ratio of Lightweight Concretes using Artificial Neural Network. Acta Phys. Pol. A 2015, 128, B-184-B-187. [CrossRef]

20. Tenza-Abril, A.J.; Villacampa, Y.; Solak, A.M.; Baeza-Brotons, F. Prediction and sensitivity analysis of compressive strength in segregated lightweight concrete based on artificial neural network using ultrasonic pulse velocity. Constr. Build. Mater. 2018, 189, 1173-1183. [CrossRef]

21. Kalman Šipoš, T.; Miličević, I.; Siddique, R. Model for mix design of brick aggregate concrete based on neural network modelling. Constr. Build. Mater. 2017, 148, 757-769. [CrossRef]

22. Demir, F. Prediction of elastic modulus of normal and high strength concrete by artificial neural networks. Constr. Build. Mater. 2008, 22, 1428-1435. [CrossRef]

23. Atici, U. Prediction of the strength of mineral admixture concrete using multivariable regression analysis and an artificial neural network. Expert Syst. Appl. 2011, 38, 9609-9618. [CrossRef] 
24. Bal, L.; Buyle-Bodin, F. Artificial neural network for predicting drying shrinkage of concrete. Constr. Build. Mater. 2013, 38, 248-254. [CrossRef]

25. Hossain, K.M.A.; Anwar, M.S.; Samani, S.G. Regression and artificial neural network models for strength properties of engineered cementitious composites. Neural Comput. Appl. 2018, 29, 631-645. [CrossRef]

26. Khademi, F.; Jamal, S.M.; Deshpande, N.; Londhe, S. Predicting strength of recycled aggregate concrete using Artificial Neural Network, Adaptive Neuro-Fuzzy Inference System and Multiple Linear Regression. Int. J. Sustain. Built Environ. 2016, 5, 355-369. [CrossRef]

27. Alengaram, U.J.; Mahmud, H.; Jumaat, M.Z. Enhancement and prediction of modulus of elasticity of palm kernel shell concrete. Mater. Des. 2011, 32, 2143-2148. [CrossRef]

28. Wee, T.H.; Chin, M.S.; Mansur, M.A. Stress-Strain Relationship of High-Strength Concrete in Compression. J. Mater. Civ. Eng. 1996, 8, 70-76. [CrossRef]

29. Guneyisi, E.; Gesoglu, M.; Booya, E. Fresh properties of self-compacting cold bonded fly ash lightweight aggregate concrete with different mineral admixtures. Mater. Struct. 2012, 45, 1849-1859. [CrossRef]

30. Bogas, J.A.; Gomes, A. A simple mix design method for structural lightweight aggregate concrete. Mater. Struct. 2013, 46, 1919-1932. [CrossRef]

31. Bogas, J.A.; de Brito, J.; Figueiredo, J.M. Mechanical characterization of concrete produced with recycled lightweight expanded clay aggregate concrete. J. Clean. Prod. 2015, 89, 187-195. [CrossRef]

32. Chi, J.M.; Huang, R.; Yang, C.C.; Chang, J.J. Effect of aggregate properties on the strength and stiffness of lightweight concrete. Cem. Concr. Compos. 2003, 25, 197-205. [CrossRef]

33. Choi, Y.W.; Kim, Y.J.; Shin, H.C.; Moon, H.Y. An experimental research on the fluidity and mechanical properties of high-strength lightweight self-compacting concrete. Cem. Concr. Res. 2006, 36, 1595-1602. [CrossRef]

34. Yang, C.C.; Huang, R. Approximate Strength of Lightweight Aggregate Using Micromechanics Method. Adv. Cem. Based Mater. 1998, 7, 133-138. [CrossRef]

35. Kayali, O. Fly ash lightweight aggregates in high performance concrete. Constr. Build. Mater. 2008, 22, 2393-2399. [CrossRef]

36. Gesoğlu, M.; Özturan, T.; Güneyisi, E. Effects of fly ash properties on characteristics of cold-bonded fly ash lightweight aggregates. Constr. Build. Mater. 2007, 21, 1869-1878. [CrossRef]

37. Aslam, M.; Shafigh, P.; Jumaat, M.Z.; Lachemi, M. Benefits of using blended waste coarse lightweight aggregates in structural lightweight aggregate concrete. J. Clean. Prod. 2016, 119, 108-117. [CrossRef]

38. Al-Sahawneh, E.I. Size effect and strength correction factors for normal weight concrete specimens under uniaxial compression stress. Contemp. Eng. Sci. 2013, 6, 57-68. [CrossRef]

39. Li, M.; Hao, H.; Shi, Y.; Hao, Y. Specimen shape and size effects on the concrete compressive strength under static and dynamic tests. Constr. Build. Mater. 2018, 161, 84-93. [CrossRef]

40. Mehta, P.K.; Monteiro, P.J.M. Concrete: Microstructure, Properties, and Materials; McGraw Hill Eduation: New York, NY, USA, 2013.

41. Lee, B.J.; Kee, S.H.; Oh, T.; Kim, Y.Y. Effect of Cylinder Size on the Modulus of Elasticity and Compressive Strength of Concrete from Static and Dynamic Tests. Adv. Mater. Sci. Eng. 2015, 2015, 580638. [CrossRef]

42. Hamad, A.J. Size and shape effect of specimen on the compressive strength of HPLWFC reinforced with glass fibres. J. King Saud Univ. Eng. Sci. 2017, 29, 373-380. [CrossRef]

43. Vakhshouri, B.; Nejadi, S. Prediction of compressive strength of self-compacting concrete by ANFIS models. Neurocomputing 2018, 280, 13-22. [CrossRef]

44. Jafari, S.; Mahini, S.S. Lightweight concrete design using gene expression programing. Constr. Build. Mater. 2017, 139, 93-100. [CrossRef]

45. Younis, K.H.; Pilakoutas, K. Strength prediction model and methods for improving recycled aggregate concrete. Constr. Build. Mater. 2013, 49, 688-701. [CrossRef]

46. Zain, M.F.M.; Abd, M.S. Multiple Regression Model for Compressive Strength Prediction of High Performance Concrete. J. Appl. Sci. 2009, 9, 155-160.

47. Tamura, S.; Tateishi, M. Capabilities of a four-layered feedforward neural network: Four layers versus three. IEEE Trans. Neural Netw. 1997, 8, 251-255. [CrossRef] [PubMed]

48. Li, J.Y.; Chow, T.W.S.; Yu, Y.L. The estimation theory and optimization algorithm for the number of hidden units in the higher-order feedforward neural network. In Proceedings of the IEEE International Conference on Neural Networks, Perth, Australia, 27 November-1 December 1995; IEEE: Piscataway, NJ, USA, 1995; Volume 3, pp. 1229-1233. 
49. Sheela, K.G.; Deepa, S.N. Review on Methods to Fix Number of Hidden Neurons in Neural Networks. Math. Probl. Eng. 2013, 2013, 1-11. [CrossRef]

50. MATLAB and Deep Learning Toolbox Release 2018b; The MathWorks, Inc.: Natick, MA, USA, 2018.

51. Kuhn, M.; Johnson, K. Applied Predictive Modeling; Springer: Berlin, Germany, 2013.

52. DeRousseau, M.A.; Kasprzyk, J.R.; Srubar, W.V. Computational design optimization of concrete mixtures: A review. Cem. Concr. Res. 2018, 109, 42-53. [CrossRef]

53. Nguyen, T.; Kashani, A.; Ngo, T.; Bordas, S. Deep neural network with high-order neuron for the prediction of foamed concrete strength. Comput. Civ. Infrastruct. Eng. 2019, 34, 316-332. [CrossRef]

(C) 2019 by the authors. Licensee MDPI, Basel, Switzerland. This article is an open access article distributed under the terms and conditions of the Creative Commons Attribution (CC BY) license (http://creativecommons.org/licenses/by/4.0/). 